\title{
LA HISTORIA LEGISLATIVA DE LA AGENCIA DE SOCIEDAD EXTRANJERA
}

[Legislative History of Foreign Companies' Agencies]

\author{
Jaime Alcalde Silva* \\ Pontificia Universidad Católica de Chile, Santiago de Chile
}

\begin{abstract}
RESUMEN
El trabajo aborda la recepción legislativa de la agencia como forma de funcionamiento de una sociedad extranjera en Chile. Su establecimiento estaba directamente relacionado con la autorización administrativa prevista para el funcionamiento de las sociedades anónimas nacionales, de manera de mantener una simetría con aquellas extranjeras que deseasen ejercer su giro en el país. Al avanzar el siglo XIX, la creciente internacionalización del comercio de seguros impulsó un cambio en el régimen de la agencia. La Ley $\mathrm{N}^{\circ} 18.046$ impuso condiciones más exigentes. La figura se extendió primero a las cooperativas, después a las compañías de seguros y finalmente a cualquier sociedad o persona jurídica con fines de lucro. Sólo quedaron
\end{abstract}

\begin{abstract}
This work addresses the legal reception of the agency as a manner in whicha foreign company operates in Chile. Its establishment was directly related to the administrative authorization that was planned for the operation of Chilean public limited companies so as to keep symmetry with those foreign companies that wished to carry out their line of business in the country. As the $20^{\text {th }}$ century went by, the increasing internationalization of insurance trade boosted a change in the agency. Law No. 18.046 set more demanding conditions. The concept first extended to cooperatives, then to insurance companies and finally to any forprofit legal company or person. Only the representatives of foreign corporations
\end{abstract}

Recibido el 5 y aceptado el 27 de mayo de 2014

* Profesor asistente de Derecho privado en la Pontificia Universidad Católica de Chile. Correo electrónico: jcalcald@uc.cl 
fuera las representaciones de corporaciones y fundaciones de origen extranjero. La tendencia actual apunta hacia una formalización automática de la agencia, sin mayor control de la autoridad pública.

Palabras Clave

Agencia - Establecimiento permanente - Sociedad extranjera - Sucursal. and foundations are not included. The current trend is the automatic formalization of the agency, without greater control from public authorities.

\section{KEYWORDS}

Agency - Permanent establishment - Foreign company - Branch.

\section{INTRODUCCIÓN}

La Ley $\mathrm{N}^{\circ} 20.382$ generalizó la disciplina de la agencia a cualquier clase de sociedad o persona jurídica con fines de lucro de origen extranjero. Hasta entonces, y en parte todavía hoy, el régimen de la agencia era más bien fragmentario, pues la figura se encontraba tratada con mayor detalle en la Ley $\mathrm{N}^{\circ} 18.046$ para el particular caso de las sociedades anónimas, que fue la sede desde donde se extrajo el material normativo para acometer la referida generalización. A ella también hacen mención los reenvíos existentes respecto de los bancos, cooperativas y compañías de seguros extranjeras que efectúan sus leyes sectoriales (artículos 32 LGB., 122 LGC y 4 bis Decreto con fuerza de ley $\mathrm{N}^{\circ} 251 / 1931$ ). Sin embargo, esta extensión dista de ser satisfactoria. La Ley $N^{\circ} 20.382$ no introdujo mejoras técnicas en el diseño de su régimen jurídico, perpetuando así los inconvenientes que ya se observaban en la Ley $\mathrm{N}^{\circ} 18.046$ respecto de la agencia de una sociedad anónima extranjera. En la actualidad no existe, por tanto, un estatuto claro de la agencia y cabe preguntarse por la conveniencia de su conservación. La materia tampoco ha despertado el interés de la doctrina científica, como se constata de la ausencia de publicaciones especializadas sobre ella fuera de los manuales en uso, ni existe jurisprudencia relevante posterior a $1982^{1}$.

${ }^{1}$ El tema ha despertado, en cambio, cierto interés entre los alumnos que preparan su tesis o memorias de prueba. Véanse: Brady Roche, E., Situación legal de las agencias de compañias extranjeras de seguros (Santiago, Universidad de Chile, 1945); Eyzaguirre Pepper, D., Agencias de sociedades anónimas extranjeras (Santiago, Pontificia Universidad Católica de Chile, 1981); Illanes Adaro, R., Agencias de sociedades anónimas extranjeras (Santiago, Universidad de Chile, 1941); Molina Moreno, G - Pellegrini Ripamonti, P., Agencia de sociedad anónima extranjera (Santiago, Pontificia Universidad Católica de Chile, 1988); Morales Alfaro, J. E. y otros, Análisis del impacto de las interpretaciones del Servicio de Impuestos Internos relacionada 
El presente trabajo indaga en la historia legislativa de la agencia como forma de actuación de una sociedad extranjera, con el propósito de extraer de ella las claves que explican las razones de su existencia y las particularidades de su régimen jurídico ${ }^{2}$. Aunque los primeros antecedentes de la figura provienen del Código de Comercio y de la Ley desociedades anónimas de 1854 que lo precedió (II), es a partir de la legislación sectorial sobre compañías de seguros (III) que ella empieza a perfilarse con los rasgos con que hoy la recibe el derecho vigente. Esos caracteres están ya presentes en los primeros reglamentos sobre sociedades anónimas dictados en 1918 y 1920 (IV), cuya disciplina sistematiza el Decreto con fuerza de ley $\mathrm{N}^{\circ} 251 / 1931$ (V) y aplica la legislación bancaria que comienza a desarrollarse por aquella época (VI). Mención especial merece el tratamiento tributario que se dispensa a la agencia con ocasión del impuesto a la renta desde mediados del siglo XX, que tiene algunas consecuencias en su configuración típica (VII). Esta evolución histórica decanta en la Ley $\mathrm{N}^{\circ} 18.046$, que se ocupa de las agencias de sociedades anónimas extranjeras prescindiendo por primera vez de una autorización administrativa de funcionamiento (VIII). Este régimen fue tomado como patrón de referencia para la generalización efectuada por la Ley $\mathrm{N}^{\circ} 20.382$, de la que ya existía un antecedente en la Ley general de cooperativas y en el Decreto con fuerza de Ley $\mathrm{N}^{\circ} 251 / 1931$ tras la reforma introducida por la Ley $\mathrm{N}^{\circ} 20.190$ (IX). Como cierre se ofrece una recapitulación sobre el sentido que hay detrás de la regulación de las agencias de sociedades extranjeras por parte del derecho chileno $(\mathrm{X})$.

\section{El Código de Comercio y la legislación PRECEdente}

Uno de los signos de atraso que se evidenciaban a fines del período indiano era la falta de conocimiento sobre las ventajas de las compañías mercantiles como una forma de reunir capitales y dar mayor desarrollo a los emprendimientos económicos ${ }^{3}$. De ellas trataba el Capítulo $10^{\circ}$ de las Ordenanzas del Consulado de Bilbao (1737), donde se regulaba un único

con las agencias extranjeras con motivo de las reinversiones contenidas en el DL 824 en su artículo 14 de la LIR (Santiago, Universidad Diego Portales, 2004); Vivanco Silva, S., Procedencia y dificultades de la declaración de quiebra de una agencia de sociedad anónima extranjera (Santiago, Pontificia Universidad Católica de Chile, 1997); ZúÑIgA Silva, M. ${ }^{a}$ C., Agencias de sociedades anónimas extranjeras. Análisis critico y ámbito de aplicación (Santiago, Pontificia Universidad Católica de Chile, 1998).

${ }^{2}$ Una primera aproximación en AlCalde Silva, J., Apuntes sobre la agencia de sociedad extranjera, en JEQUIER LEHUEDÉ, E. (editor), Estudios de derecho comercial (Santiago, LegalPublishing/ThomsonReuters, 2014) [en prensas], II.

${ }^{3}$ Rojas Sánchez, G. (editor), Historia del gremialismo empresarial (Santiago, Confederación de la Producción y el Comercio, 2000), p. 26. 
tipo social de índole personalista similar a la actual sociedad colectiva. Hubo que esperar hasta mediados del siglo XIX para que el país contase con una regulación específica sobre sociedades anónimas ${ }^{4}$. Antes de la promulgación de la Ley de 8 de noviembre de 1854, esta clase de sociedades sólo podían ser constituidas merced a una ley especial y en atención a un giro considerado de interés nacional (artículo 151 CPol. 1833) . Tal fue el caso de la sociedad creada para el establecimiento de un ferrocarril entre las ciudades de Santiago y Valparaíso, en la cual podían participar todos los habitantes del país (Ley de 28 de agosto de 1851). Esta situación cambió a partir de la Ley de 1854, pues desde entonces la constitución de una sociedad anónima y la prueba de su existencia dependían del otorgamiento de una escritura pública (artículo 2), que debía contar con el correspondiente decreto del gobierno que autorizase su funcionamiento (artículo 6). La función que éste desempeñaba era usualmente burocrática, y se limitaba a consultar con el Fiscal Judicial de la Corte Suprema que los estatutos estuviesen redactados según la ley (artículo 7), de suerte que sólo en raras ocasiones se cuestionaba la organización interna de la empresa o los derechos otorgados a los accionistas, como ella misma ordenaba (artículo 8).

En las disposiciones transitorias de esta ley se hacía mención a las sociedades extrajeras, que venían caracterizadas como sociedades ya existentes y que no habían sido aprobadas por especial acuerdo de la legislatura. Ellas tenían un plazo de seis meses contados desde la promulgación de la Ley de sociedades anónimas para solicitar la autorización necesaria para operar en Chile (artículo 1 transitorio). De no solicitarse dentro de ese plazo, la sociedad sería considerada como colectiva, y los socios quedarían personal y solidariamente obligados por los contratos y operaciones posteriores (artículo 3 transitorio).

La Ley de 1854 rigió hasta la entrada en vigor del Código de Comercio (1865), del que originalmente formaba parte ${ }^{6}$. En este último existía una

\footnotetext{
${ }^{4}$ ANDrades Rivas, E., La sociedad anónima en la tradición jurídica hispano-indiana, en Revista de Estudios Histórico-Jurídicos, 33 (2011), pp. 438-440.

${ }^{5}$ Sobre ella, su texto y antecedentes: Brahm García, E., José Gabriel Ocampo y las fuentes de la Ley sobre sociedades anónimas. El proceso de codificación comercial chileno en un ejemplo, en Revista de Estudios Histórico-Juridicos, 19 (1997), pp. 189-254, ahora en José Gabriel Ocampo y la codificación comercial chilena (Santiago, Universidad de los Andes, 2000), I, pp. 13-50 y 387-447.

${ }^{6}$ La Ley de 1854 hacía parte del proyecto de Código de Comercio en que trabajaba José Gabriel Ocampo (1798-1882) desde 1852, pero la importancia que la clase dirigente atribuía al espíritu de asociación hizo adelantar su promulgación separada. Este hecho no impidió que Ocampo continuase perfeccionando su texto ("Mensaje" del Código de Comercio, $\$ 44$ ). Por ejemplo, el artículo 6 de la Ley de 1854 preveía dos formas de constitución de una sociedad anónima: por decreto del gobierno y por ley. Esta segunda modalidad era la única posible tratándose de bancos de descuento y circu-
} 
referencia expresa a la agencia de sociedad anónima extranjera, aunque no se le dispensaba mayor atención que aquella relativa a fijar su forma de establecimiento y las consecuencias de su actuación irregular ${ }^{7}$. A este respecto, el código repetía la regla existente para cualquier sociedad anónima en el artículo 427, según la cual las compañías extranjeras no podían establecer agentes en Chile sin la previa autorización del presidente de la República (artículo 468, I). De esta forma, el agente que obraba sin la respectiva autorización quedaba personalmente obligado al cumplimiento de los contratos que hubiese celebrado y sometido a las responsabilidades contempladas por el propio código, sin perjuicio de la acción a que hubiese lugar contra dichas compañías (artículo 468 II). Estas dos reglas permanecieron vigentes hasta su modificación por la Ley 17.308, de 1 de julio de 1970, que reemplazó el texto del artículo 468. El nuevo artículo sólo mantuvo la regla referida a las consecuencias que se seguían de la actuación del agente sin haber obtenido el permiso de funcionamiento de la autoridad competente, que desde entonces pasó a ser la Superintendencia de Sociedades Anónimas, cuya resolución debía ser visada por el Ministro de Hacienda.

En los manuscritos del Proyecto de Código de Comercio, José Gabriel Ocampo (1798-1882) menciona dos fuentes para el artículo 468, que también sirvieron de antecedente para los artículos transitorios de la Ley de sociedades anónimas de $1854^{9}$.

La primera de ellas es el Règlement du ministre de l'intérieur sur lexécution de larticle 37 de code de commerce, relatif aux sociétés anonymes, de 31 de diciembre de 1807, que Ocampo cita como "Inst. Minist. de 1808" (sic) ${ }^{10}$. En Francia, las sociedades anónimas habían sido reguladas por el Code de

lación (artículo 7). El código finalmente promulgado conservó sólo el primer supuesto (artículo 427), en concordancia con la precedente Ley de bancos de emisión.

${ }^{7}$ La Ley de 23 de julio de 1860 sobre bancos de emisión aludía a las agencias a propósito de la sanción por no exhibir los libros, cajas y carteras del banco cuando así fuese requerido por la autoridad administrativa. En ella incurrían por igual "[e]lpropietario, director, comisionado o ajente [sic] cualquiera de un banco de emisión”. La generalidad con que esta norma venía redactada lleva a pensar que la referencia atañía tanto a la persona a quien se confiaba una sucursal abierta por un banco chileno en otro punto del país (artículo $3 \mathrm{~N}^{\circ} 3$ ), como a aquella a quien una sociedad extranjera encargaba la apertura de una agencia en Chile (artículo 3 in fine).

${ }^{8}$ FeRnÁndeZ Villamayor, A., La sociedad anónima con las reformas introducidas por la Ley núm. 17.308 de 1970 (Santiago, Editorial Jurídica de Chile, s.d. [pero 1970]), p. 161.

${ }^{9}$ Brahm García, José Gabriel Ocampo, I, cit. (n. 5), pp. 444 y 447.

${ }^{10}$ Devilleneuve, L. M.- Carrete, A. A., (editores), Recueil général des lois et des arrêts avec notes et commentaires, I : Lois annotées. 1789-1830 (Paris, Administration du Recueil général de lois et arrêts, 1851), p. 764. 
Commerce de 1807, cuyo artículo 37 disponía que ellas sólo existirían por autorización del rey y con su aprobación por el acto que las constituía, el que debía ser expedido en la forma prevista en los reglamentos administrativos. El mentado reglamento contenía el procedimiento para la obtención de dicha autorización de constitución y funcionamiento. Este procedimiento era aplicable también a las sociedades anónimas por entonces existentes, las cuales tenían el plazo de seis meses, contado desde el 1 de enero de 1808, para solicitar la autorización de funcionamiento en los términos señalados en el Reglamento (artículo $7^{\circ}{ }^{11}$. Sin embargo, Ocampo omitió mencionar (quizá por desconocimiento) la existencia de la Ley de 23 de mayo de 1863, que autorizó la creación de sociedades de responsabilidad limitada (sociétés à responsabilité limitée), y de las cuales no hay mención en la legislación chilena hasta la Ley $\mathrm{N}^{\circ} 3.918$, de 14 de marzo de $1923^{12}$. Ellas se caracterizaban porque no requerían la autorización gubernamental del artículo 37 del Code de Commerce (artículo $1^{\circ}$ ), debían estar formadas por al menos siete socios (artículo 2) y tener un capital inferior a 20.000.000 FRF (artículo $3^{\circ}$ ).

La segunda fuente citada por Ocampo es "Card. Tom. 2. Pag. 521", que corresponde al tomo II de la revista El Derecho moderno fundada en 1847 por Francisco de Cárdenas y Espejo (1817-1898) ${ }^{13}$. En la página indicada existe una referencia a una Real Orden de 9 de febrero de 1847, donde se contiene el "encargo a los tribunales de comercio que suspendan el autorizar la formación de nuevas sociedades anónimas", del que se da cuenta detallada en el cuerpo de la revista ${ }^{14}$. El Código de Comercio español de 1829 había prescrito que el establecimiento de una sociedad anónima estaba sujeto al examen y aprobación de su escritura y reglamentos por parte del tribunal de comercio del territorio donde se constituía, sin los cuales no podía llevarse a efecto (artículos 276 y 293). La mentada Real Orden mandaba, pues, a los tribunales de comercio "interinamente y hasta que las cortes aprueben un proyecto de ley de sociedades anónimas suspender el conceder su autorización para la formación de ninguna de ellas" ${ }^{15}$. La suspensión de nuevas autoriza-

\footnotetext{
${ }^{11}$ Ocampo menciona como fuente el artículo 6, pero transcribe enseguida el texto traducido del artículo 7. La errata se halla en el manuscrito encuadernado con el título de Código de Comercio, I-2, p. 177, que se conserva en la Biblioteca del Colegio de Abogados de Chile A.G.

${ }^{12}$ Sobre esta ley y sus antecedentes: Claro Solar, L., La ley $N^{o} 3.918$ de 14 de marzo de 1923 sobre sociedades de responsabilidad limitada, en Revista de Derecho y Jurisprudencia, 20 (1923), pp. 1-17.

${ }^{13}$ CÁrdenas, F. (editor), El Derecho moderno. Revista de Jurisprudencia y Administración (Madrid, Ramón Rodríguez de Rivera, 1847), II.

${ }^{14}$ Esta referencia viene incluida en la sección sobre "Legislación comercial, industrial y agrícola" del "Índice de leyes y decretos publicados en 1847" (p. 521).

${ }^{15}$ CÁRdenas, El derecho moderno, cit. (n. 13), II, p. 71.
} 
ciones se prolongó por menos de un año, porque muy pronto fue aprobada la Ley de 28 de enero de 1848 sobre sociedades mercantiles por acciones, complementada por un Reglamento dado el 17 de febrero. En ella se preveía que la constitución de esta clase de sociedades se hacía en virtud de una ley o de un real decreto (artículo 1), el que sólo se había de conceder cuando el objeto de la sociedad fuese de utilidad pública, y nunca cuando pretendiera monopolizar subsistencias o artículos de primera necesidad (artículo 4) ${ }^{16}$. Las sociedades constituidas con anterioridad tenían un plazo de dos meses para regularizar su situación mediante la obtención del correspondiente real decreto (artículo 19), trascurrido el cual se considerarían disueltas de pleno derecho (artículo 43 del Reglamento).

De lo anterior se sigue que, no obstante la coincidencia de fuentes, no existía una mención expresa a la agencia en la Ley de sociedades anónimas de 1854 y sólo se trataba de ella en el proyecto final de Código de Comercio. Al parecer, el origen directo del artículo $468 \mathrm{CCom}$. se halla en la nota marginal agregada al artículo 599 (antes 606) de un borrador anterior, referido a la responsabilidad de los accionistas (más tarde artículo $456 \mathrm{CCom}$.), que el código generalizó para cualquier sociedad anónima. Ahí se decía: "Las compañias estranjeras [sic] de seguros terrestres o maritimas no podrán establecer en la República sin la autorización del Gobierno./Los agentes que obrasen por esas compañias sin haber obtenido esa autorización quedarán personalmente obligados al cumplimiento de los contratos que celebrasen y sometidos a las responsabilidades precedentemente establecidas" ${ }^{17}$.

\section{LA LEGISLACIÓN SOBRE COMPAÑÍAS DE SEGUROS}

Pese a que el contrato de seguro venía tratado en el capítulo $22^{\circ}$ de las Ordenanzas del Consulado de Bilbao, el período indiano se caracterizó por la ausencia de compañías dedicadas al aseguramiento contra riesgos y accidentes ${ }^{18}$. La libertad de comercio con todas las naciones proclamada por la Primera Junta de Gobierno mediante el Bando de 21 de febrero de 1811, complementado después por un reglamento de 1813, no supuso una situación nueva para el país, sino que comportó el desenlace de una

${ }^{16}$ Es de suponer que esta ley fue conocida por Ocampo, pese a que no hay referencia a ella en el "Mensaje" del Código de Comercio. Por ejemplo, la forma de constitución de una sociedad anónima (artículos 6, 7 y 8 de la Ley de 1854) guarda exacta correspondencia con los artículos 1 y 2 de la Ley española de sociedades mercantiles por acciones. Sin embargo, como fuente se cita un trabajo anterior aunque coincidente publicado en El Derecho moderno. Cfr. Brahm García, José Gabriel Ocampo, cit. (n. 5), I, p. 411.

${ }^{17}$ Ibíd., pp. 536-537.

${ }^{18}$ Rojas SÁnCHEz, Historia del gremialismo empresarial, cit. (n. 3), p. 26. 
serie de grandes trasformaciones ocurridas a lo largo del siglo precedente. $\mathrm{Su}$ virtud consistió en perfeccionar el orden existente por entonces, pero sin variaciones sustanciales en la situación comercial del período indiano tardío ${ }^{19}$. Debido al momento histórico que se vivía, el comercio marítimo no aumentó durante esa década y las expediciones que llegaron a las costas del país venían cubiertas por seguros contratados en sus puertos de origen, y no ofrecían campo para hacer prosperar iniciativas de carácter nacional. Alrededor de 1820, la actividad aseguradora comenzó a penetrar en el país con algunas compañías inglesas que establecieron sucursales en el puerto de Valparaíso, principalmente dedicadas a los seguros marítimos ${ }^{20}$. Uno de los primeros agentes aseguradores fue Gabriel Lafond de Lurcy (1802-1876), que trabajó con la firma Dubern Rojo y Cía. (1823) y, probablemente, con George Lyon Thomas (1803-1866) ${ }^{21}$. La experiencia adquirida le permitió ingresar algunos años después en la Compañía de Seguros Marítimos de Francia, de la cual llegó a ser director.

Hacia 1852 surgió entre algunos comerciantes la idea de crear una compañía de seguros propiamente chilena. Por impulso de Agustín Edwards Ossandón (1815-1878), ella fue formalizada en Valparaíso por escritura pública de 17 de enero de 1853 y autorizado su funcionamiento por Decreto supremo de 10 de febrero de ese año ${ }^{22}$. Tomó por nombre Compañía Chilena de Seguros y tuvo por giro asegurar contra incendios y riesgos marítimos ${ }^{23}$. Promulgada la Ley de sociedades anónimas de 1854, la sociedad procedió de inmediato a acomodar su estructura de acuerdo con las disposiciones de la nueva ley (Decreto supremo $\mathrm{N}^{\circ} 485$, de 24 de mayo de 1855, del Ministerio de Hacienda). El establecimiento de esta compañía incentivó la creación de otras, como La República (1855) y La Mutualidad (1860).

El Código de Comercio reguló el contrato de seguro en sus distintas mo-

${ }^{19}$ Por todos: Villalobos Rivera, S., Comercio y contrabando en el Río de la Plata y en Chile. 1700-1811 (Buenos Aires, EUDEBA, 1965), p. 140.

${ }^{20} \mathrm{~S} \mathrm{CHadlich}, \mathrm{U}$., Antecedentes históricos y doctrinarios de la legislación de seguros en Chile (Santiago, Editorial Universitaria, 1963), p. 118.

${ }^{21}$ Torechio, D., Hechos de Chile (Santiago, Sociedad Filatélica de Chile, 1982), p. 221.

${ }^{22}$ Agustín Edwards fundó también el Banco de A. Edwards y Cía., sucesor de una oficina de préstamos establecida en 1852 (Decreto supremo $\mathrm{N}^{\circ} 10$, de 5 de enero de 1867, del Ministerio de Hacienda).

${ }^{23}$ Con este nombre operó hasta 1905 cuando varias compañías de seguros, encabezadas por "La Chilena", se fusionaron para dar nacimiento a "La Chilena Consolidada". Constituida por escritura pública de 9 de agosto de 1905, sus estatutos fueron aprobados por el DS 3546, de 6 de septiembre de 1905, del Ministerio de Hacienda (Decreto supremo $\mathrm{N}^{\circ}$ 1.449, de 31 de marzo de 1906, del Ministerio de Hacienda). 
dalidades (libro IV, título $\left.8^{\circ}\right)^{24}$. Esta nueva disciplina fue pionera e innovó en las costumbres que el comercio de seguros había introducido en el país a través de las cláusulas usuales en las pólizas de aquella época ${ }^{25}$. Sin embargo, fuera de la disciplina de los derechos y obligaciones del asegurador nacidos del contrato, nada se dispuso en él respecto a la organización jurídica de quien asumía la calidad de asegurador (artículo $513 \mathrm{CCom}$.), que podía ser tanto una persona natural como una persona jurídica (artículo $512 \mathrm{CCom}$.), y ella permaneció ignorada hasta comienzos del siglo $\mathrm{XX}^{26}$.

El minucioso tratamiento del Código de Comercio tuvo sí efectos colaterales, porque incentivó el desarrollo del comercio de seguros y dio origen a nuevas compañías chilenas, como La Nacional (1871), La Concepción (1886), La Previsora (1889), La Tarapacá (1889), La Talcahuano (1892), La Internacional (1893), La Santiago de Chile (1893), etcétera ${ }^{27}$. Paralelamente, comenzaron a establecerse en el país agentes de compañías extranjeras, la mayoría de los cuales lo hacía sin cumplir con ningún requisito legal y sin el ingreso efectivo de capital. A fines del siglo XIX funcionaban en el país alrededor de dieciséis compañías nacionales y veintisiete extranjeras ${ }^{28}$. La coexistencia entre ellas no era pacífica, pues las compañías extranjeras, con la vitalidad que les permitía su estructura societaria, su enorme capacidad económica y la experiencia comercial acumulada, acaparaban la mayor y mejor parte de la contratación de seguros, obteniendo ingentes ganancias por concepto de primas. Las empresas nacionales debían conformarse con el resto. Además, las compañías extranjeras actuaban más o menos concertadas o formando asociaciones parciales en la fijación de las tarifas de las primas y la estipulación de las condiciones generales de las pólizas ${ }^{29}$. Pronto los problemas derivados de este desequilibrio de mercado comenzaron a ser abordados con algunas medidas de protección a favor de las empresas chilenas.

${ }^{24} \mathrm{El}$ contenido de esta regulación fue sustituido por la Ley $\mathrm{N}^{\circ} 20.667$, de 9 de mayo de 2013, cuya autoría corresponde al profesor Osvaldo Contreras Strauch. Cfr. Historia de la Ley 20.667 (Valparaíso, Biblioteca del Congreso Nacional, 2013), p. 5.

${ }^{25}$ Cfr. "Mensaje" del Código de Comercio, $\$ \$ 48,49$ y 50.

${ }^{26} \mathrm{La}$ calidad del asegurador era relevante para calificar los contratos celebrados como actos de comercio o actos civiles (artículo $3 \mathrm{~N}^{\circ} 9 \mathrm{CCom}$.). Sin embargo, por el propio funcionamiento del comercio de seguros, no hay constancia de su ejercicio por personas naturales con posterioridad a la vigencia del código.

${ }^{27}$ Espinosa Moder, A., Régimen legal del comercio de seguros en Chile (Santiago, Imprenta Electra, 1928), pp. 74-75; y EspinosA MODER, E., Los seguros en Chile (memoria de prueba, Santiago, Facultad de Comercio y Ciencias Económicas, Universidad Católica de Chile, 1932), pp. 19-20.

${ }^{28} \mathrm{~S}$ CHADlich, Antecedentes históricos, cit. (n. 20), p. 121.

${ }^{29}$ La Chilena Consolidada, Reseña histórica de sus noventa años de vida. 18531943 (Valparaíso, Imprenta Universo, 1944), p. 47. 
La primera medida provino del propio gremio de los aseguradores, que comisionó a Francisco Antonio Pinto, Luis Dávila y Benjamín Dávila Larraín para que gestionasen ante el gobierno la elaboración de un proyecto de ley destinado a establecer la uniformidad obligatoria de las condiciones de las pólizas emitidas por aseguradores nacionales y extranjeros. El gobierno y el Congreso compartían la inquietud, dado que el comercio informal de seguros repercutía desfavorablemente en la economía del país por la fuga de capitales hacia el exterior. Para dar solución a este problema, en la sesión ordinaria de 22 de agosto de 1885, el diputado Julio Zegers Samaniego (1830-1918) presentó una moción destinada a regular la situación de las agencias de compañías de seguros extranjeras ${ }^{30}$. Constataba que éstas se establecían en el país sin constituir ninguna garantía, no estaban sujetas a vigilancia especial y pagaban una patente máxima de 200 CLP, mientras que una sociedad anónima chilena con un capital de 10.000.000 CLP pagaba un impuesto anual de 30.000 CLP. Proponía, entonces, que las agencias de compañías extranjeras no pudiesen establecerse ni funcionar en Chile sino sujetándose a todas las leyes que regían las sociedades anónimas, y que desde su establecimiento pagasen la contribución mobiliaria que correspondía a esa clase de sociedades (artículo 1 del proyecto). Además, la cuota de su capital que dichas agencias debían hacer efectivo antes de comenzar sus operaciones no podía ser inferior al $10 \%$ de su capital nominal (artículo 1 del proyecto). Las agencias existentes contarían con un plazo de seis meses para regularizar su existencia, y las que no lo hicieran entrarían en liquidación y les sería prohibida toda nueva operación bajo multa de 100 a 1000 CLP por cada caso de contravención (artículo 1 transitorio del proyecto). No hubo, empero, mayor discusión sobre esta materia hasta que a mediados de la década siguiente se produjo la quiebra en Inglaterra de la compañía de seguros La Económica, cuyo agente en Valparaíso se limitó a informar a los asegurados, sin devolver las sumas pagadas.

Para precaver la ocurrencia de situaciones parecidas, el 2 de enero de 1896 se dictaron dos decretos supremos. El primero de ellos disponía que los agentes de bancos y compañías de seguros extranjeras tenían la obligación de presentar semestralmente al Ministerio de Hacienda un balance de sus operaciones en Chile, en la forma establecida para las sociedades anónimas nacionales (artículo 1). Esos balances debían ser publicados en los mismos casos en que, por ley, habían de hacerlo dichas sociedades (artículo 2). El decreto comenzaba su vigencia a partir del mes de enero de 1896 respecto de los balances correspondientes al segundo semestre del año anterior (artículo

${ }^{30}$ Congreso Nacional, Sesiones ordinarias de la Cámara de Diputados de 1885 (Santiago, Imprenta Nacional, 1885), p. 477. 
3). El segundo decreto buscaba hacer efectivo el artículo $461 \mathrm{CCom}$., referido a la obligación de los administradores de presentar a la asamblea general una memoria razonada sobre la situación de la sociedad, junto con un balance y un inventario preciso y detallado de las existencias, remitiendo una copia a la intendencia y otra al juzgado de comercio (artículo 1). El Subsecretario de Hacienda publicaría esas memorias y balances en el Diario Oficial acompañado de un listado nominal de las sociedades anónimas que no hubiesen aportado la documentación requerida (artículo 4).

Tres años antes, en la sesión de 31 de julio de 1893, el Senado había adoptado el acuerdo de proponer a la Cámara de Diputados la formación de una Comisión mixta para reglamentar la situación de la industria salitrera en sus relaciones con el Estado y para determinar la contribución que debían pagar las instituciones comerciales extranjeras, como también las garantías que debían exigirse a las agencias que procediesen en representación de sociedades extranjeras que no tenían capital efectivo en el país. Tal comisión se constituyó y funcionó durante varios años, aunque sin cumplir su cometido. Con posterioridad se presentaron otros proyectos que abordaban esta materia ${ }^{31}$. De ellos interesan principalmente dos.

El 28 de abril de 1896, el presidente Jorge Montt Álvarez (1846-1922) envió al Congreso Nacional un proyecto que reglamentaba la constitución y funcionamiento de las compañías de seguros extranjeras, las que debían constituir un capital de garantía ascendente a 400.000 CLP. Trataba asimismo de igualar la situación de las compañías nacionales y extranjeras respecto del pago de impuestos y de la presentación y publicación de los balances. El proyecto pasó a la Comisión de Hacienda, que recomendó su aprobación con algunas modificaciones; pero su tramitación se detuvo.

El 3 de junio de 1898, el gobierno presentó un nuevo proyecto que refundía todos los anteriores. Su discusión fue ardua y se extendió por varios años. Las compañías extranjeras, si bien aceptaban la obligación de ingresar al país parte de su capital, estimaban que la suma propuesta (ahora sólo 250.000 CLP) era muy elevada; pero sobre todo se oponían al establecimiento de un impuesto diferenciado que las gravaba en mayor proporción que a las compañías nacionales. Finalmente, el proyecto fue aprobado y se convirtió en la Ley $\mathrm{N}^{\circ} 1.712$, de 19 de noviembre de 1904. Ella establecía la exigencia de que una compañía extranjera sólo podía funcionar o establecer agencias en Chile tras ser aprobada por el Presidente de la República (artículo 1, I). Para la obtención de esta autorización, la compañía interesada debía $i$ ) justificar que se había organizado con arreglo a las leyes del país en que fue fundada; y

\footnotetext{
${ }^{31}$ Véase una relación de ellos en UGarte VIAL, J. (director), Historia e indice de las leyes (Santiago, Biblioteca del Congreso Nacional, 1950), II, pp. 249-250.
} 
ii) invertir en bienes raíces, libres de gravamen, situados en Chile o en valores nacionales, o depositar en la Casa de Moneda o en la oficina que designase el Presidente de la República la cantidad que le correspondiese según la categoría o clase que se hubiese asignado y la especie de seguros de que la compañía se ocupase (artículo 2) ${ }^{32}$. Una vez expedido el decreto de autorización, la compañía extranjera se consideraba domiciliada en Chile y quedaba sometida a las autoridades judiciales y administrativas y, en general, a la legislación del país para todas las obligaciones que contrajere (artículo 8, I). Su representación judicial, sin restricción de facultades, correspondía al agente principal que tuviese en Chile, cualesquiera que fuesen los términos de las pólizas o de los poderes conferidos a éste (artículo 8, II) ${ }^{33}$. El incumplimiento de las obligaciones establecidas en la ley autorizaba al presidente de la República para revocar el decreto que autorizaba la existencia o funcionamiento de la compañía de seguros (artículo 1, III) ${ }^{34}$. Las agencias de compañías extranjeras quedaban, en fin, bajo la supervisión de inspectores de Oficinas Fiscales designados por el presidente de la República, quienes tenían el cometido de vigilar las operaciones, libros y cuentas de dichas agencias, y también de las compañías nacionales (artículo 11) 35 $^{35}$.

Esta ley no cumplió cabalmente el propósito con que fue elaborada, pues los bajos montos de la garantía que debían constituir las compañías extranjeras no impidieron la instalación de agencias de dudosa solvencia y la salida de capitales chilenos hacia el exterior. Al comenzar el segundo cuarto del siglo $\mathrm{XX}$, la mayoría de los aseguradores eran agencias de compañías extranjeras, principalmente inglesas, francesas, alemanas, españolas y estadounidenses, que obraban a través de representantes también extranjeros domiciliados

${ }^{32}$ La Ley $\mathrm{N}^{\circ} 1.712$ distinguía entre compañías de seguro de primera y segunda clase para efectos de determinar el monto de la inversión exigida en el artículo 2, y detallaba las diversas vías para cumplir con dicho depósito (artículos 3, 4 y 5). La categoría asignada a una compañía incidía también en el valor de la patente anual que debía pagar (artículo 7).

${ }^{33}$ Véase, respecto del artículo 468 CCom., la sentencia de la Corte de Apelaciones de Valparaíso, de 20 de marzo de 1885, en Gaceta de los Tribunales, 2445 (1885), p. 1463.

${ }^{34} \mathrm{El}$ artículo 6 de la Ley $\mathrm{N}^{\circ} 1.712$ establecía que el depósito efectuado por la compañía extranjera como condición para operar en Chile no podía ser retirado sin que previamente se justificase, con un aviso de seis meses, que habían terminado los riesgos u otras operaciones que motivaron dicha garantía; pero cabía la posibilidad de que el Presidente de la República autorizase la sustitución de algunos de los valores depositados por otros equivalentes. Esta regla se conservó en la jurisprudencia de la Superintendencia de Sociedades Anónimas para cualquier sociedad de esta clase (Oficio $\mathrm{N}^{\circ} 11$, de 3 de enero de 1939).

${ }^{35}$ Véase la nota 43. 
en Chile ${ }^{36}$. Por esa razón, tras dos décadas de vigencia, la Ley 1712 fue derogada por el artículo 96 de la Ley $\mathrm{N}^{\circ} 4.228$, de 21 de diciembre de 1927, sobre nacionalización del comercio de seguros. Desde su promulgación, el comercio de asegurar o cubrir a base de primas cualesquier clase de riesgo sólo pudo hacerse en Chile a través de sociedades anónimas nacionales de seguros, expresamente autorizadas para ello en sus estatutos, o por entidades de carácter mutual, organizadas sin fines de lucro y con la aprobación del presidente de la República (artículo 37) ${ }^{37}$. Las nuevas empresas que se constituyesen con ese giro recibirían el nombre de "compañías de seguros" y habían de adoptar la forma de una sociedad anónima (artículo 39). Las sociedades filiales de agencias extranjeras que ya estuviesen establecidas en Chile venían consideradas, empero, como compañías nacionales para todos los efectos legales (artículo 85).

El Decreto con fuerza de ley $\mathrm{N}^{\circ} 251 / 1931$ conservó la reserva del comercio de seguros a favor de las sociedades anónimas nacionales dedicadas a ese giro (artículo 4), pero dedicó uno de sus párrafos a tratar la situación de las agencias de compañías extranjeras (título $1^{\circ}$, párrafo $4^{\circ}$, artículos 52 55). El principio que ahí se sigue es que las agencias ya radicadas en Chile podían continuar con sus operaciones sobre su misma base de organización, pero debían conformarse en el ejercicio de su giro en el país a los acuerdos y compromisos celebrados o que se celebraren con el presidente de la República (artículo 52). Pese a las reformas de liberalización introducidas por el Decreto-ley $\mathrm{N}^{\circ} 3.057$, de 10 de enero de 1980, esta prohibición se mantuvo en vigor hasta 2007, cuando la Ley 20.190 dispuso que se intercalara un artículo 4 bis, como parte de una serie de medidas para el fomento de la industria de capital riesgo y de modernización del mercado de capitales de acuerdo a los estándares de la $\mathrm{OECD}^{38}$. Este nuevo artículo mantiene la reserva del comercio de seguros a favor de sociedades constituidas en Chile, pero permite el establecimiento de agencias de compañías extranjeras de conformidad con la Ley 18.046, siempre que se solicite autorización previa a

${ }^{36}$ Véase una nómina de las sociedades anónimas extranjeras establecidas en el país, en funciones en 31 de diciembre de 1922, en FERnÁndEZ OJEDA, M. (coordinador), Disposiciones vijentes en Chile sobre instituciones de crédito i comerciales: bancos, seguros, sociedades, comercio, contribuciones (Santiago, s.e., 1923), pp. 544-549.

${ }^{37} \mathrm{El}$ Decreto con fuerza de ley $\mathrm{N}^{\circ} 251 / 1931$ reservó el comercio de asegurar riesgos a base de primas exclusivamente a las sociedades anónimas nacionales de seguros y reaseguros (artículo 4), prohibiendo desde entonces el establecimiento de tontinas, chatelusianas, mixtas y de asociaciones mutuales que tengan por objeto asegurar riesgos de cualquier naturaleza, a base de cuotas y no de primas, o cuando empleen estas últimas y no puedan garantizar los beneficios que ofrecen (artículo 5).

${ }^{38}$ Historia de la Ley 20.190 (Valparaíso, Biblioteca del Congreso Nacional, 2007), pp. 11-12. 
la Superintendencia de Valores y Seguros (artículos 126 LSA.). Para proteger a los acreedores, se reproducen los resguardos previstos para las agencias de bancos extranjeros en el artículo 34 LGB.

\section{Los REgLAMENTOS DE SOCIEDADES ANÓNIMAS DE 1918 Y 1920}

El tratamiento de las sociedades anónimas en el Código de Comercio acababa con el artículo 469, que preveía la redacción de un reglamento que determinaría la manera de ejecutar tales disposiciones. El primer Reglamento de sociedades anónimas civiles y comerciales fue sancionado por el Decreto supremo $\mathrm{N}^{\circ} 1.322$, de 12 de junio de 1918, del Ministerio de Hacienda, que tuvo gran importancia por el diseño que confirió a la disciplina de este tipo social ${ }^{39}$. Por ejemplo, introdujo reglas que debían ser incorporadas en los estatutos como una condición indispensable para obtener la autorización administrativa de funcionamiento (artículos 1-4); y utilizó por primer vez el término "directores", en reemplazo de la expresión "mandatarios" (artículo 457 CCom.), para mentar a los encargados de la administración de la sociedad (título $\left.2^{\circ}\right)^{40}$.

El título $10^{\circ}$ de este Reglamento estaba dedicado a las sociedades anónimas extranjeras (artículos 60-64). En él se mantuvo el mecanismo de constitución de una agencia previsto en el Código de Comercio, pero se agregaron algunos requisitos de carácter formal que debían ser cumplidos tanto por la sociedad extranjera para obtener su reconocimiento en Chile (artículo 60) como por el agente antes de comenzar a desempeñar su cometido (artículo 61). Estos requisitos ampliaban aquellos exigidos por la Ley $\mathrm{N}^{\circ} 1.712$ para la constitución de una agencia de compañía de seguros, pues prescribían que se acompañase la documentación referida a la sociedad que deseaba constituir

\footnotetext{
${ }^{39}$ Hasta la Ley $\mathrm{N}^{\circ} 18.046$ (artículo 1, II), las sociedades anónimas podían ser civiles o comerciales (artículo 2061 IV CC.). Eran de esta segunda clase aquellas que se formaban para negocios que la ley calificada de actos de comercio; las demás se reputaban sociedades civiles (artículo 2059 II CC.).

${ }^{40}$ Esta terminología se conservó en el Decreto con fuerza de ley $\mathrm{N}^{\circ} 231 / 1931$. Aunque la expresión persiste hasta hoy, su sentido ha variado. Con anterioridad a la Ley 18.046, los administradores eran los directores y no el directorio, por lo que éste no era más que el conjunto de mandatarios temporales y revocables a quienes se había conferido la administración de una sociedad de acuerdo con lo señalado en los estatutos (artículo 457 CCom.). Ahora, en cambio, la administración corresponde propiamente al directorio en cuanto órgano colegiado de la sociedad, que sólo puede ser revocado en su totalidad por una junta ordinaria o extraordinaria de accionistas (artículos 31, 38, 39 y 40 LSA.). De esto se sigue que la responsabilidad del directorio sea solidaria (artículo 133 LSA.), y que cada director en particular sólo pueda eximirse de ella en la medida que conste en el acta su oposición al acto lesivo (artículo 48, IV LSA.).
} 
la agencia, incluido el poder bajo el cual actuaría el agente (artículo 60) y la demostración del hecho de que el capital social se hallaba suscrito y pagado al menos en una tercera parte (artículo 64); y también que el propio agente efectuase una serie de declaraciones destinadas a asegurar la regularidad de las operaciones que emprendería en Chile (artículo 61) ${ }^{41}$. Además, era necesario comprobar anualmente el cumplimiento de los presupuestos societarios tenidos en cuenta para conceder la autorización de funcionamiento ante el inspector de Oficinas Fiscales encargado de las sociedades anónimas (artículo 62), debiendo dar publicidad a través del Diario Oficial a los certificados aportados a ese efecto (artículo 63).

El Reglamento de 1918 fue derogado por otro contenido en el Decreto supremo $\mathrm{N}^{\circ} 3.030$, de 13 de diciembre de 1920, del Ministerio de Hacienda. Este nuevo reglamento sobre sociedades anónimas, más acabado que el anterior, estaba dividido en dos partes: una dedicada a las sociedades nacionales (artículo 1-43) y otra referente a las sociedades extranjeras (artículo 44-48). Respecto de estas últimas, no sólo se mencionaba la documentación que había de acompañar a la solicitud de autorización (artículo 45) y el contenido de la declaración jurada que debía emitir el agente (artículo 46), sino que también se prescribía el cumplimiento de un requisito de fondo al que se supeditaba el otorgamiento de dicha autorización (artículo 44). Éste consistía en una revisión de los estatutos por parte del presidente de la República, para determinar si en ellos existían disposiciones que garantizasen los derechos de los accionistas y de los terceros que contratasen con la sociedad (artículo 44), en términos similares a lo previsto para las sociedades nacionales (artículos 1-5). De ahí se seguía que el permiso para establecer una agencia en Chile pudiese ser revocado cuando el presidente de la República estimaba que la sociedad no ofrecía las mismas garantías que en la época de su autorización, fuese por pérdida de una parte importante del capital social o del fondo de reserva que debía constituirse en Chile, fuese por modificaciones inconvenientes en sus estatutos o por cualquier otro motivo grave (artículo 48).

\section{El Decreto con fuerza de Ley N² 251/1931, “Sobre COMPAÑÍAS DE SEGUROS, SOCIEDADES ANÓNIMAS Y BOLSAS DE COMERCIO", Y SUS REGLAMENTOS}

Merced a las sugerencias de la Misión Kemmerer, Chile se incorporó a la tendencia mundial existente a comienzos del siglo XX que propugnaba

${ }^{41}$ Esas reglas se correspondían sustancialmente con las previstas hoy en los artículos 121 y 122 LSA., con excepción de la autorización administrativa previa. 
una mayor intervención del Estado en la actividad económica ${ }^{42}$. Uno de los textos promulgados con ese fin fue el Decreto con fuerza de ley $\mathrm{N}^{\circ} 251$, de 22 de mayo de 1931, sobre compañías de seguros, sociedades anónimas y bolsas de comercio. En términos generales, esta nueva regulación no introdujo cambios significativos en la disciplina sobre sociedades anónimas contenida en el Código de Comercio y en el reglamento que lo desarrollaba. Su mayor novedad fue la elevación a rango legal de una serie de normas ya presentes en el Reglamento de 1920 y, especialmente, la creación de un organismo de control con competencia conjunta sobre el mercado bursátil y de seguros y sobre la actividad de las sociedades anónimas. Este organismo había nacido del Decreto con fuerza de ley $\mathrm{N}^{\circ} 135$, de 9 de mayo de 1931, dependía del Ministerio de Hacienda y recibió el nombre de Superintendencia de Compañías de Seguros, Sociedades Anónimas y Bolsas de Comercio. Tenía a su cargo la aplicación del propio Decreto con fuerza de ley $\mathrm{N}^{\circ} 251 / 1931$, la superior fiscalización de los negocios de las compañías de seguros, el control de las operaciones bursátiles y la vigilancia de las sociedades anónimas desde su escritura de constitución hasta el término de su liquidación (artículo 1), condensando así las funciones que por entonces ostentaban la Inspección General de Sociedades Anónimas y Operaciones Bursátiles, creada por la Ley N ${ }^{\circ} 4.404^{43}$, y la Superintendencia de Compañías de Seguros, establecida

${ }^{42}$ Los trabajos de la Misión Kemmerer fueron recopilados bajo el título de Legislación bancaria y monetaria (Santiago, Imprenta Universitaria, 1926), ahora reeditado como vol. 82 de la Biblioteca Fundamentos de la Construcción de Chile (Santiago, Biblioteca Nacional/Pontificia Universidad Católica de Chile/Cámara Chilena de la Construcción, 2011), con un estudio preliminar de Juan Pablo Couyoumdjian (pp. ix-l).

${ }^{43}$ La Ley N ${ }^{\circ} 4.404$, de 10 de septiembre de 1928, creó la Inspección General de Sociedades Anónimas y Operaciones Bursátiles, a quien se confío la vigilancia y la fiscalización de las sociedades anónimas y en comandita por acciones, y de las compañías mineras constituidas por instrumento público o privado (artículo $100 \mathrm{~N}^{\circ} 3$ del Código de Minería de 1888), y que tuviesen más de veinticinco socios. Dicho organismo sucedía a la Inspección de Sociedades Anónimas y de Sociedades en Comandita por Acciones, creada por el Decreto-ley $\mathrm{N}^{\circ} 158$, de 18 de diciembre de 1924, y cuyo cometido era ejercer la vigilancia pública a la que se refería el artículo 436 CCom. Esta norma prescribía que el presidente de la República podía nombrar un comisario que vigilase las operaciones de los administradores sociales y le diese cuenta de la inejecución o infracción de los estatutos. Al él correspondía fijar asimismo la remuneración de este funcionario, la cual sería pagada por la sociedad. Las funciones de estos comisarios de sociedades anónimas fueron reguladas por primera vez mediante el reglamento sancionado por el Decreto supremo de 21 de abril de 1887, del Ministerio de Hacienda. La Ley de 12 de septiembre de ese año modificó el artículo $436 \mathrm{CCom}$., para precisar que el nombramiento de tales comisarios se haría en caso de que se considerase necesario y recaería en algún Inspector de Oficinales Fiscales (oficio creado por la Ley de 20 de 
por la Ley $\mathrm{N}^{\circ}$ 4.228. Este organismo permaneció en funciones hasta 1980, cuando fue sustituido por la Superintendencia de Valores y Seguros de que trata el Decreto-ley $\mathrm{N}^{\circ} 3.538$, de 23 de diciembre de ese año, y que cumple funciones algo diversas ${ }^{44}$.

Para lo que aquí interesa, y fuera de lo dicho respecto de las compañías de seguros (artículos 52-55), el Decreto con fuerza de ley N²51/1931 reguló la constitución de sociedades anónimas en Chile por extranjeros (artículos 117 y 118) y, con particular detalle, el procedimiento para el establecimiento en el país de agencias de sociedades extranjeras (artículos 120-127). En esta nueva disciplina se mantuvo la exigencia de autorización administrativa previa (artículo 120), y también los requisitos formales (artículos 122 y 123) y de fondo (artículos 121 y 126) que se debían cumplir para que tal autorización fuese concedida, así como la obligación de dar publicidad a su balance (artículo 127).

En un principio, el Decreto con fuerza de ley $\mathrm{N}^{\circ}$ 251/1931 derogó el Reglamento de sociedades anónimas de 1920 (artículo 162). Esto significaba que el gobierno debía dar cumplimiento al mandato del artículo 469 CCom. y dictar un nuevo reglamento. Como no lo hizo, la Ley $\mathrm{N}^{\circ} 6156$, de 13 de enero de 1938, restableció la vigencia del Reglamento de 1920 en todo aquello que no fuese contrario a la disciplina por entonces existente sobre sociedades anónimas o estuviese derogado por otras leyes (artículo 1 transitorio). Pero este restablecimiento duró sólo unos meses, porque el Decreto supremo $\mathrm{N}^{\circ}$ 1.521, de 3 de mayo de 1938, del Ministerio de Hacienda, sancionó un nuevo Reglamento de sociedades anónimas nacionales y extranjeras, que sustituyó al anterior. En él las sociedades anónimas extranjeras venían tratadas en el Título VI, que se ocupaba de regular la publicidad del decreto que autorizaba el establecimiento de una agencia en Chile (artículo 47) y de aquel que revocaba o cancelaba tal autorización (artículo 48), así como del cambio de representante que efectuase la sociedad (artículo 49). Este reglamento fue reemplazado a su vez por un texto refundido contenido en el DS 4705, de 30 de noviembre de 1946, del Ministerio de Hacienda, que sin embargo no alteró la disciplina de la agencia prevista en el DS 1521/1938 (artículos 47, 48 y 49). Este último, así como las leyes que desarrollaba (Código de Comercio y Decreto con fuerza de ley $\mathrm{N}^{\circ} 251 / 1931$ ), fueron derogados por la Ley $\mathrm{N}^{\circ}$ 18.046 (artículo 145).

octubre de 1852), los cuales no tenían por este motivo derecho a sobresueldo. Dicha norma quedó tácitamente derogada por el artículo 83 del Decreto con fuerza de ley $\mathrm{N}^{\circ}$ 251/1931, que fijaba las atribuciones y obligaciones de la Superintendencia en relación con las sociedades anónimas, al ser incompatible la dualidad de supervisión.

${ }^{44}$ Véase: Caballero Germain, G., Presente y futuro de la Superintendencia de Valores y Seguros, en Revista Chilena de Derecho Privado, 11 (2008), pp. 9-42. 


\section{LA LEGISLACIÓN BANCARIA}

Por los años 1837, 1838 y 1839, las autoridades de la provincia de Coquimbo pusieron en conocimiento del gobierno que algunas casas comerciales de los distritos mineros habían comenzado a emitir ciertos vales que circulaban como billetes convertibles en moneda legal, con los cuales pagaban los salarios de sus trabajadores y aun algunos impuestos, bajo pretexto de la carencia de moneda oficial ${ }^{45}$. Este requerimiento hizo que el Ministerio de Hacienda dictase el DS 140, de 3 de noviembre de 1839, sobre bancos públicos. En él se disponía que ninguna persona podía establecer bancos, ni emitir vales o billetes de créditos, sin que previamente solicitase autorización del gobernador y la municipalidad respectiva, expresando la cantidad que deseaba emitir a la circulación, y rindiese fianzas hipotecarias a favor de esas autoridades para asegurar el exacto y puntual pago en moneda corriente de los billetes emitidos (artículo 1) ${ }^{46}$. Nada se preveía, en cambio, respecto de la forma societaria que debía adoptar un banco de emisión.

El 23 de julio de 1860 se promulgó la Ley sobre bancos de emisión, que establecía ciertas garantías mínimas relacionadas con la confección de papel moneda en ausencia de un organismo oficial de control (por ejemplo, artículos 6 y 29), reservando al presidente de la República la autorización de funcionamiento para esta clase de instituciones (artículo 5) ${ }^{47}$. Tampoco

${ }^{45}$ Estas emisiones privadas circulaban en paralelo con el dinero metálico acuñado por la Casa de Moneda (creada por Real Cédula de 1 de octubre de 1743), cuya primera Ley orgánica se contiene en la Ley de 23 de enero de 1883. El Banco Central sólo fue creado en 1925 (Decreto-ley N 486) y no alcanzó autonomía hasta 1989 (Ley N ${ }^{\circ}$ 18.880), en concordancia con lo dispuesto en la Constitución Política de 1980 (artículos 87 y 88). Una década antes de estas emisiones privadas, y como una forma de atraer a los mineros que preferían vender sus pastas a los exportadores de la zona antes que a la Casa de Moneda, se dictó el Decreto supremo de 27 de septiembre de 1827, del Ministerio de Hacienda, por el que se estableció una sala de amonedación en la ciudad de La Serena con el mismo tipo, ley y peso que aquella que se acuñaba en Santiago. Su funcionamiento se extendió entre 1827 y 1830 , cuando el congreso plenipotenciario constituido en esta última ciudad ordenó cerrar esta sección debido a que las monedas acuñadas no cumplían con los requerimientos de gramaje, trazado y tratamiento del metal. Hubo además razones políticas relacionadas con el apoyo prestado al vencido general Ramón Freire (1787-1851) por los funcionarios de esa dependencia (Decreto supremo de 12 de octubre de 1830).

${ }^{46} \mathrm{La}$ Ley de 20 de diciembre de 1865 confirió determinados privilegios a los billetes librados por los bancos de emisión y reguló la forma de acogerse a ellos. La Ley de 23 de julio de 1878 estableció la inconvertibilidad monetaria.

${ }^{47}$ La autoría de esta ley correspondió casi en su integridad a Jean Gustave Courcelle-Seneuil (1813-1892), economista francés que entre 1855 y 1862 se desempeñó como profesor de economía política en la Universidad de Chile y consultor del Minis- 
preveía esta ley que los bancos debiesen constituirse como sociedades anónimas. Prueba de ello es, por ejemplo, que el Banco de A. Edwards y Cía. fue fundado en 1867 como una sociedad colectiva y sólo se transformó en sociedad anónima en 1913 (Decreto supremo $\mathrm{N}^{\circ} 3.065$, de 27 de octubre de 1867, del Ministerio de Hacienda). Debido a una serie de dificultades políticas y económicas posteriores a la Revolución de 1891, la libertad de emisión fue suprimida a partir de la Ley $\mathrm{N}^{\circ} 1.054$, de 31 de julio de 1898 , que autorizó de nuevo la circulación de billetes fiscales de curso forzoso sin convertibilidad (restablecida en 1895), y del Decreto supremo $\mathrm{N}^{\circ} 1.533$, de 6 de julio de 1898, del Ministerio de Hacienda, que ordenó la suspensión de pagos en las oficinas de los bancos de emisión, pese a lo cual continuaron en operaciones dieciséis bancos, diez de ellos en regiones ${ }^{48}$.

Para lo que aquí interesa, especial importancia reviste el Decreto supremo $\mathrm{N}^{\circ} 47$, de 11 de febrero de 1874, del Ministerio de Hacienda, por el que se autorizó al Banco de Londres, México y Sud-América para que estableciese en Valparaíso una agencia que se ocupase de sus operaciones comerciales, menos la de emitir billetes ${ }^{49}$. La apertura de esta agencia despertó una fuerte oposición de parte de los comerciantes del puerto, la mayoría de los cuales eran accionistas de los bancos locales. De hecho, la sucursal comenzó su funcionamiento sin haber obtenido todavía la autorización gubernamental y fue clausurada por la Intendencia. El deterioro de la economía durante el período de crisis que comienza en la década de 1870 , y sobre todo el riesgo de inconvertibilidad de la moneda materializado en la Ley de 23 de julio de 1879 , llevaron al cierre material de la agencia en $1878^{50}$.

Algo más perdurable fue la agencia de The Bank of Tarapacá and London Ltd. (Decreto supremo de 30 de abril de 1889, del Ministro de Hacienda).

terio de Hacienda. En ese país, la autorización administrativa para el funcionamiento de un banco venía exigida por la Ley de 14 de abril de 1803 (24 de germinal del año XI). Véase: Courcelle-Seneuil, J. G., Bancos de circulación, en Revista de Ciencias $i$ Letras, 1 (1857), pp. 37-50.

${ }^{48}$ La cuestión se relaciona con la controversia entre oreros y papeleros, que se prolonga hasta el siglo XX. Sobre ella: Rivas VicuÑa, M., Historia politica y parlamentaria de Chile. 1891-1920 (Santiago, Biblioteca del Congreso Nacional, 1964), I, pp. 22-24, 55, 139-140, 166-167 y 601; y II, pp. 32, 266 y 384.

${ }^{49} \mathrm{El}$ Decreto supremo $\mathrm{N}^{\circ} 258$, de 21 de diciembre de 1871, del Ministerio de Hacienda, aprobó los estatutos del Banco Nacional de Bolivia. Éste fue fundado para operar como banco de emisión, depósitos, descuentos y préstamos en la República de Bolivia y en Valparaíso, pero quedó constituido en el país como sociedad anónima y no como agencia.

${ }^{50}$ Couyoumdjian, J. R., Los británicos en las finanzas/British Influence on Financial Management, en PraIn, M. (editor), Legado británico en Valparaiso/British Legacy in Valparaiso (Santiago, RIL, 2010), p. 87. 
Este banco había sido fundado el año anterior en la ciudad de Londres por un grupo de capitalistas relacionados con negocios salitreros en Chile, el principal de los cuales era John Thomas North (1842-1896). Su objetivo principal era operar como banquero de explotaciones que estaban casi exclusivamente radicadas en la provincia de Tarapacá, creada en 1884 tras su anexión del Perú, las que pertenecían en un $70 \%$ a capitales ingleses. El banco abrió su oficina principal en Iquique, que fue confiada a John Dawson (antes gerente de la sucursal del Banco de Valparaíso en esa ciudad), y pronto otras en Valparaíso, Pisagua, Punta Arenas, Concepción y Antofagasta. Por Decreto supremo de 18 de mayo de 1901, del Ministerio de Hacienda, complementado por otro de 27 de junio del mismo año, este banco cambió su nombre por el de Banco de Tarapacá y Argentina Ltdo., con autorización para mantener sus agencias en el país. Con posterioridad, pasó a llamarse Banco Anglo-sudamericano Ltdo. (Decreto supremo $\mathrm{N}^{\circ} 923$, de 30 de abril de 1907, del Ministerio de Hacienda) y, tras la liquidación de éste, Banco de Londres y América del Sud Ltdo. (Decreto supremo $\mathrm{N}^{\circ} 2182$, de 17 de junio de 1937, del Ministerio de Hacienda ${ }^{51}$. Este último operaba también a través de agentes en Chile, primero con el nombre de Banco de Londres, Buenos Aires y Río de la Plata Ltdo. (Decreto supremo de 3 de enero de 1907, del Ministerio de Hacienda), y desde 1924 con el ya mencionado (Decreto supremo $\mathrm{N}^{\circ} 1147$, de 4 de junio de 1924, del Ministerio de Hacienda). Como parte de las políticas de estatización de la banca anunciadas por el Presidente Salvador Allende Gossens (1908-1973) el 30 de diciembre de 1970, al Banco de Londres y América del Sud Ltdo. le fue cancelada la autorización para mantener agencias en el país (Resolución $N^{\circ}$ 2079, de 19 de octubre de 1971, de la Superintendencia de Bancos), a la vez que su propiedad era adquirida

${ }^{51}$ El Banco Anglo-Sudamericano Ltdo. había adquirido en 1912 otro banco británico, el Banco de Londres, México y Sud-América, que había vuelto a Chile, primero a través del Banco Mobiliario (constituido por Decreto supremo $\mathrm{N}^{\circ} 228$, de 15 de diciembre de 1869, del Ministerio de Hacienda) liquidado en 1907 y, desde 1911, del Banco Español de Chile (Decreto supremo No 1156, de 24 de abril de 1900, y Decreto supremo $\mathrm{N}^{\circ}$ 5.406, de 30 de diciembre de 1905, ambos del Ministerio de Hacienda). La absorción de otros bancos continuó en los años siguientes: en 1917 tomó el control del Commercial Bank of Spanish America, que tenía una fuerte presencia en Colombia y Centroamérica, y más tarde del British Bank of South America, que operaba en Brasil. En 1920 adquirió también el 60\% de la propiedad del Banco de A. Edwards y Cía. Sin embargo, las crisis del salitre y la Gran Depresión de 1929 afectaron profundamente al banco, y en 1936 entró en proceso de liquidación. Muchas de sus sucursales, como ocurrió en Chile, fueron adquiridas por el Banco de Londres y América del Sud Ltdo. Este último comenzó a su vez a ser absorbido de forma progresiva por el Lloyds Bank, fundado en 1765, hasta que en 1986 quedó completamente integrado en él. 
por el Banco O'Higgins, estatizado poco antes (Resolución exenta $\mathrm{N}^{\circ} 78$, de 27 de agosto de 1971, de la Superintendencia de Bancos).

Más tarde instalaron sus agencias el Banco de Chile y Alemania (Decreto supremo de 18 de diciembre de 1895, del Ministerio de Hacienda) y el Banco Alemán Transatlántico (Decreto supremo $\mathrm{N}^{\circ} 5$, de 7 de enero de 1896, del Ministerio de Hacienda). En el primer cuarto del siglo XX lo hicieron el Banco Germánico de América del Sud (Decreto supremo de 13 de abril de 1910, del Ministerio de Hacienda), el Banco Mercantil de Bolivia (Decreto supremo de 18 de noviembre de 1914, del Ministerio de Hacienda), The National City Bank of the New York (Decreto supremo $\mathrm{N}^{\circ}$ 62, de 18 de enero de 1916, del Ministerio de Hacienda), el Banco Ítalo-belga (Decreto supremo $\mathrm{N}^{\circ} 2319$, de 17 de septiembre de 1920, del Ministerio de Hacienda), el Banco Holandés de la América del Sud (Decreto supremo N $^{\circ} 2615$, de 29 de octubre de 1920, del Ministerio de Hacienda) y el Banco Francés e Italiano para América del Sud (Decreto supremo $\mathrm{N}^{\circ} 2.833$, de 30 de diciembre de 1921, del Ministerio de Hacienda) ${ }^{52}$. El Banco Alemán Transatlántico y el Banco Germánico de América del Sud fueron cerrados, liquidados y sus bienes incautados por el gobierno con ocasión de la ruptura de relaciones diplomáticas con los países del Eje (Decreto supremo $\mathrm{N}^{\circ} 402$, de 19 de enero de 1944, del Ministerio de Hacienda) ${ }^{53}$.

Varios años después se instalaron en Chile el Banco Popular Colombo Chileno (Decreto supremo 6861, de 26 de agosto de 1955, del Ministerio de Hacienda), el Banco do Brasil (Decreto supremo $N^{\circ} 955$, de 4 de abril de 1963, del Ministerio de Hacienda), el Banco de la Nación Argentina (Resolución $\mathrm{N}^{\circ} 68$, de 16 de mayo de 1980, de la Superintendencia de Bancos e Instituciones Financieras), el Chicago Continental Bank (Resolución $\mathrm{N}^{\circ} 132$, de 3 de septiembre de 1980, de la Superintendencia de Bancos e Instituciones Financieras), el DnB NOR Bank ASA (Resolución N ${ }^{\circ} 128$,

\footnotetext{
${ }^{52}$ Por reforma de sus estatutos pasó a denominarse después Banco Francés e Italiano para la América del Sur-Sudameris (Decreto supremo $\mathrm{N}^{\circ} 229$, de 19 de enero de 1966, del Ministerio de Hacienda), cuya autorización de funcionamiento fue cancelada en 1972 (Resolución N 13, de 4 de mayo de 1972, de la Superintendencia de Bancos).

${ }^{53}$ Respecto del Banco Alemán Trasatlántico, véase la sentencia de la Corte de Apelaciones de Santiago 30 de diciembre de 1963, en Revista de Derecho y Jurisprudencia, 62 , sec. $2^{a}$, pp. 1-52). La causa no llegó a ser conocida por la Corte Suprema, porque el banco se desistió del recurso de casación en el fondo que había interpuesto en contra de esta sentencia. La razón de este desistimiento fue la Ley $\mathrm{N}^{\circ} 15.673$, de 3 de septiembre de 1964, por la cual se facultó al presidente de la República para emitir a favor de dicha institución un pagaré de hasta por 1.400.000 USD en pago de los saldos actualizados resultantes de su liquidación.
} 
de 26 de junio de 2008, de la Superintendencia de Bancos e Instituciones Financieras), entre otros ${ }^{54}$.

La proliferación de agencias de bancos extranjeros durante los primeros años del siglo XX trajo consigo una reacción normativa de parte del gobierno del Presidente Arturo Alessandri Palma (1868-1950). El Decreto supremo $\mathrm{N}^{\circ} 2.381$, de 31 de octubre de 1921, del Ministerio de Hacienda, complementó el Reglamento de sociedades anónimas de 1920 en lo que atañía a los bancos extranjeros que deseaban establecer en el país una sucursal de acuerdo al artículo $468 \mathrm{CCom}$. En esos casos, la agencia sólo se autorizaba si se acreditaba un capital efectivo superior a 10.000.000 CLP en moneda nacional (artículo 1); constituía un fondo de reserva con un porcentaje no inferior al $10 \%$ de las utilidades de su balance anual (artículo 2); y quedaba regida por la Ley 23 de junio de 1860 sobre bancos de emisión y por las demás leyes o reglamentos que existiesen o se dictasen en lo sucesivo (artículo 3). Este texto tuvo una corta vigencia y fue derogado por el Decreto supremo $\mathrm{N}^{\circ} 5$, de 11 de enero de 1922, del Ministerio de Hacienda, que declaró inaplicable el Reglamento de sociedades anónimas respecto de los bancos, por su insuficiencia para garantizar la efectividad del capital y las demás condiciones exigidas por la Ley de 23 de junio de 1860 . Al año siguiente, la Ley $\mathrm{N}^{\circ} 3.918$ permitió la constitución de sociedades de responsabilidad limitada con un máximo de 50 socios, pero excluyó de su giro la actividad bancaria (artículo 2, II).

Pese a estas iniciativas, las instituciones bancarias continuaron careciendo de una regulación orgánica hasta el segundo cuarto del siglo XX, cuando por sugerencia de la Misión Kemmerer se dictó el Decreto-ley $\mathrm{N}^{\circ} 559$, de 26 de septiembre de 1925, modificado por el Decreto-ley $\mathrm{N}^{\circ} 782$, de 21 de diciembre del mismo año, que contenía la primera Ley general de bancos que rigió en Chile. En ella existía un párrafo dedicado a las "agencias de empresas bancarias extranjeras", que integraba el título 4 dedicado a la administración de los bancos comerciales. Ese párrafo sólo contenía un artículo, y en él indicaba que por banco extranjero se entendía toda empresa bancaria que hubiese sido autorizada por un gobierno extranjero o que en cualquier otra forma hubiese obtenido de tal derechos legales de existencia (artículo 82). Para operar en Chile, un banco debía constituirse como sociedad anónima, correspondiendo al Superintendente del ramo el otorgamiento de la autorización de existencia (artículo 10) ${ }^{55}$. La situación de los bancos extranjeros que quisiesen constituir sucursales en el país no era la excepción, de suerte que debían aportar junto a su solicitud tanto los antecedentes generales

${ }^{54} \mathrm{Al}$ respecto y con mayor desarrollo: Aránguiz Donoso, H., Notas para el estudio de los bancos extranjeros en Chile: 1889-1971, en Historia, 27 (1993), pp. 19-68.

${ }^{55}$ Esta Superintendencia reemplazó al Inspector de Bancos (artículos 1 y 83 del Decreto-ley $\mathrm{N}^{\circ} 559 / 1924$ ), cargo creado por la Ley $\mathrm{N}^{\circ} 2.621$, de 30 de enero de 1912. 
exigidos por el Reglamento de sociedades anónimas como aquellos especiales previstos por la Ley general de bancos (artículo 11). Además, la agencia no podía operar si el capital que le había sido asignado no era equivalente a aquel que el artículo 59 exigía para los bancos nacionales de igual categoría, y tenía la obligación de aumentarlo en un plazo no superior a dos años (artículo 18).

Esta ley rigió prácticamente sin modificaciones hasta 1960. Ese año, y haciendo uso de las facultades extraordinarias que le había concedido la Ley $\mathrm{N}^{\circ}$ 13.305, el presidente Jorge Alessandri Rodríguez (1896-1986) revisó su texto para darle una consistencia más orgánica y adaptada a las necesidades del momento. El fruto de esa revisión fue el Decreto con fuerza de ley $\mathrm{N}^{\circ}$ 252, de 4 abril de 1960, que fijó el nuevo texto de la Ley general de bancos. En él, empero, no hubo innovaciones en lo que atañía a las agencias de bancos extranjeros. Para operar en el país, éstos debían solicitar una autorización al Ministerio de Hacienda, acompañando a la solicitud la documentación exigida en general para las sociedades anónimas y aquella específica prevista para las instituciones bancarias (artículo 29). Una vez constituidas en Chile de forma legal, estas agencias gozaban de un trato igualitario con los bancos nacionales y quedaban sujetos a la jurisdicción de los tribunales chilenos (artículo 30). La legislación de sociedades anónimas era de aplicación subsidiaria ${ }^{56}$.

A comienzos de la década de 1980 existían en Chile veinticinco bancos nacionales y trece bancos extranjeros, junto con dieciocho sociedades financieras. Entre 1981 y 1983, el país sufrió la crisis más profunda que haya afectado su sistema bancario y financiero. Ella ocasionó la liquidación de seis bancos, la absorción de otros dos, la fusión del Banco Empresarial de Fomento con dos sociedades financieras para dar origen al Banco del Desarrollo, y la intervención estatal de catorces bancos (entre ellos el Banco de Chile y el Banco de Santiago) y siete instituciones financieras, a la par de una reducción de un $14,3 \%$ en el PIB, una tasa de desempleo de $27,3 \%$ y una devaluación del peso en un $18 \%$. Esto supuso una reordenación del panorama bancario hacia fines de 1983, cuando operaban en el país diecinueve bancos nacionales, diecinueve bancos extranjeros y sólo siete sociedades financieras. La experiencia de esta grave situación sirvió para adecuar el texto de la Ley general de bancos en 1986, con el objeto de incorporar algunas disposiciones de carácter preventivo, ciertos cambios sustanciales a la regulación y supervisión de las empresas bancarias y financieras, y una delimitación clara de las actividades propias de su giro $\left(\text { Ley } \mathrm{N}^{\circ} 18.576\right)^{57}$.

${ }^{56}$ Sentencia de la Corte de Apelaciones de Santiago, de 30 de diciembre de 1963, cit. (n. 53) (considerando $43^{\circ}$, p. 29).

${ }^{57}$ Sobre las causas de esta crisis, sus consecuencias y reacciones: HeLd, G. - JiméNEZ, L. F., Liberalización, crisis y reforma del sistema bancario: 1974-99, en FFRENCHDavis, R. - Stallings, B. (editores), Reformas, crecimiento y politicas sociales en Chile 
El texto actual de la Ley general de bancos proviene del Decreto con fuerza de ley $\mathrm{N}^{\circ} 3$, de 19 de diciembre de 1997, que refundió el Decreto con fuerza de ley $\mathrm{N}^{\circ} 252 / 1960$ y el Decreto-ley $\mathrm{N}^{\circ} 1.097$, de 25 de julio de 1975, que contenía la Ley orgánica de la Superintendencia de Bancos e Instituciones Financieras, merced a la habilitación conferida por la Ley $\mathrm{N}^{\circ} 19.528$. Ahí se distinguen dos formas de actuación de un banco extranjero en el país: la sucursal y la representación.

El procedimiento establecido para la apertura de una sucursal o agencia sigue de cerca la que ha sido la tendencia histórica en la materia y es semejante al previsto para la constitución de un banco (artículo 32 LGB. ${ }^{58}$. Sin embargo, se admite también que un banco extranjero opere en Chile a través de un representante, que se desempeña como un mero agente de negocios, sin constituir formalmente una sucursal (artículo 33 LGB.) ${ }^{59}$. La existencia de esta figura se remonta al Decreto con fuerza de ley $\mathrm{N}^{\circ} 252 / 1960$ (artículo 35) y permite a los bancos extranjeros traer negocios al país, conocer el mercado e informar a sus principales, sin necesidad de incurrir en los costes que significa la instalación de una sucursal operativa ${ }^{60}$. Puede así, por ejemplo, publicitar en el país los productos o servicios de crédito de sus casas matrices que determine la Superintendencia, ajustándose a las normas generales que ésta dicte (artículo 33 LGB.). La representación debe ser autorizada por este organismo, quien estudiará los antecedentes del banco solicitante y aprobará o desechará la solicitud, teniendo especialmente en consideración dos factores: (i) la importancia relativa de la empresa bancaria en su país de origen y (ii) el interés que representa para Chile la instalación de la representación en lo que atañe al desarrollo de su comercio exterior ${ }^{61}$. Concedida la autorización, el poder del representante debe ser inscrito en el Registro de

desde 1973 (Santiago, LOM/CEPAL, 2001), pp. 138-162; y ReInstein, A. - RoSENDE, F., Reforma financiera en Chile, en LARRAÍn, F. - VERGARA, R. (editores), La transformación económica de Chile (Santiago, CEP, 2000), pp. 359-371.

${ }^{58}$ Los términos "sucursal” y "agencia” son sinónimos según el Oficio $N^{\circ} 1781$, de 24 de marzo de 1982, de la Superintendencia de Valores y Seguros.

${ }^{59}$ Esta distinción permite sostener que el agente es en verdad un órgano de la sociedad (equivalente al gerente general), y no un mero agente de negocios en el sentido del artículo $3 \mathrm{~N}^{\circ} 7 \mathrm{CCom}$. La diferencia entre ambos estriba en que aquel opera a nombre y por cuenta de la sociedad extranjera, mientras que este último lo hace por cuenta de su mandante pero a nombre propio, como parte de su giro comercial. Véase la sentencia de la Corte de Apelaciones de Santiago de 28 de enero de 1970, en Fallos del Mes, 134, 9, pp. 357-360.

${ }^{60}$ Morand Valdivieso, L., Legislación bancaria (5a edición, Santiago, Editorial Jurídica de Chile, 2008), p. 23.

${ }^{61}$ Véase la "Minuta para establecer una oficina de representación de banco extranjero en Chile" preparada por la Superintendencia de Bancos e Instituciones Financie- 
Comercio del lugar donde ejercerá sus funciones (artículos $22 \mathrm{~N}^{\circ} 5 \mathrm{CCom}$. y $7 \mathrm{~N}^{\circ} 5$ RRC.). Por su parte, la Superintendencia puede revocar dicha autorización en cualquier momento si la representación realiza actos propios del giro bancario (mencionados en el artículo 69 LGB.) o si su subsistencia fuere inconveniente (artículo 33 LGB.).

\section{EL TRATAMIENTO TRIBUTARIO DE LAS AGENCIAS}

La Ley $\mathrm{N}^{\circ} 3.996$, de 2 de enero de 1924, estableció por primera vez de forma orgánica un impuesto a la renta dividido en seis categorías ${ }^{62}$, a los que se añadió un impuesto global complementario de tasa progresiva merced al Decreto-ley $\mathrm{N}^{\circ} 330$, de 18 de marzo de 1925 . Tras varias modificaciones, su texto fue refundido y sistematizado por la Ley $\mathrm{N}^{\circ} 5.169$, de 30 de mayo de 1933. Ella fue derogada por la Ley 8419, de 10 de abril de 1946, dictada en cumplimiento de la habilitación de la Ley $\mathrm{N}^{\circ} 8.283$, cuyo texto definitivo se contiene en el Decreto supremo $\mathrm{N}^{\circ} 2.106$, de 10 de mayo de 1954, del Ministerio de Hacienda. Esta última fue sustituida a su vez por el artículo 5 de la Ley $\mathrm{N}^{\circ} 15.564$, de 14 de febrero de 1964, que estructuró el impuesto a la renta sobre bases muy parecidas a las existentes en la actualidad. Ahí se hacía referencia al impuesto adicional que gravaba las rentas de fuente chilena de las agencias, sucursales $\mathrm{u}$ otras formas de establecimientos permanentes de empresas extranjeras que operaban en Chile (artículos 32 y 60 núm. 1). Se aludía, pues, a los rendimientos que producían en el país las agencias de empresas extranjeras, sin circunscribir el concepto a un tipo determinado de sociedad (como en el Código de Comercio, el Decreto con fuerza de ley $\mathrm{N}^{\circ} 251 / 1931$ y el Reglamento de sociedades anónimas), y sirviéndose de un concepto amplio y de creación tributaria como era el de "establecimiento permanente", del cual la agencia, la sucursal, la oficina y la representación no comportaban más que especies ${ }^{63}$. Con algunos desarrollos, este régimen

ras [actualizada por última vez el 26 de agosto de 2009) y disponible en su sitio web http://www.sbif.cl/) [fecha de consulta: 11 de abril de 2014].

${ }^{62}$ Respecto del derecho anterior: CATTANEO EscobAR, I., Naturaleza jurídica de las normas sobre impuesto a las rentas en la República, previos a la Ley No. 3996, en Revista Chilena de Historia del Derecho, 23 (2011), pp. 193-200.

${ }^{63} \mathrm{El}$ término no es desconocido para el Código Civil, que habla de "establecimientos durables" (por ejemplo, una tienda, una botica, una fábrica, un taller, una posada, una escuela) como una manera de exteriorizar el ánimo de permanecer en un determinado lugar (artículo 64). Su utilización con connotaciones fiscales aparece por primera vez en el "Borrador de modelo de tratado sobre doble tributación y evasión fiscal" preparado por la Sociedad de las Naciones (1928). Sobre la historia del concepto: KoBETSKY, M., International Taxation of Permanent Establishments. Principles and Policy (Cambridge, CUP, 2011), pp. 106-151. 
de tributación fue recogido en el Decreto-ley $\mathrm{N}^{\circ} 824$, de 31 de diciembre de 1974, que derogó la Ley de impuesto a la renta contenida en el artículo 5 de la Ley $\mathrm{N}^{\circ} 15.564$ (artículos 10, 12, 38, 41 A, 41 B, 41 C, 41 E, 58 y 74).

La institución de los establecimientos permanentes pertenece al ámbito del derecho tributario internacional y está directamente relacionada con la doble tributación ${ }^{64}$. Para el Servicio de Impuestos Internos, por tal hay que entender la extensión de la actividad de una empresa extranjera en Chile, mediante el establecimiento de una oficina en donde se desarrolle una actividad formal que asume la representación total de la empresa, pudiendo cerrar negocios en los términos que se indiquen ${ }^{65}$. Esto supone que una entidad que no es residente en un Estado opera mediante un establecimiento permanente cuando dispone en él, de forma continuada o habitual, instalaciones o lugares de trabajo de cualquier índole, en los cuales realiza todo o parte de su actividad, o cuando actúa en dicho Estado por medio de un agente autorizado para contratar en nombre y por cuenta del contribuyente final ${ }^{66}$. A estos efectos, se consideran como renta imputable al establecimiento permanente los rendimientos de actividades económicas desarrolladas por él mismo, aquellos otros que deriven de elementos patrimoniales afectos a su actividad, y las ganancias o incrementos derivados de elementos patrimoniales vinculados funcionalmente al establecimiento. De esta manera, estas bases fijas en territorio de otro Estado se gravan casi de la misma manera que las entidades residentes, garantizando el efectivo cumplimiento del principio de no discriminación consagrado en los tratados de inversión y de doble tributación.

\section{LA LEY N 18.046 “SOBRE SOCIEDADES ANÓNIMAS”}

La Ley $\mathrm{N}^{\circ} 18.046$ tiene el mérito de haber sistematizado el régimen de la sociedad anónima a través de un único cuerpo legal caracterizado por su claridad, armonía y estructura interna. Sin embargo, el propósito de esta

${ }^{64}$ Véase, por ejemplo, Albornoz Robertson, J., El establecimiento permanente, en Revista der Derecho, 11 (Valdivia, 2000), pp. 7-12; y Maldonado Vargas, C., Extensión del concepto de establecimiento permanente en el derecho chileno y su adecuación a los convenios modelo OCDE (tesis para optar al grado de Magíster en Derecho Tributario, Santiago, Universidad de Chile, 2012).

${ }^{65}$ Véase, entre otros, los Oficios $N^{\circ} 303$, de 28 de enero de 1998, y N².205, de 5 de junio de 2000, del Servicio de Impuestos Internos.

${ }^{66}$ Véase el concepto de establecimiento permanente que da el artículo 5 tanto de la Convención modelo de las Naciones Unidas sobre la doble tributación entre países desarrollados y países en vías de desarrollo (1980 y 2011) como del Modelo de Convenio de la OCDE para evitar la doble imposición (1992, con varias actualizaciones posteriores). 
ley era preferentemente económico, pues con ella se perseguía perfeccionar el mercado de capitales y convertir las sociedades anónimas en mecanismos efectivos de inversión ${ }^{67}$. Esto explica que ella fuese promulgada junto a otra dedicada a regular el mercado de valores (Ley $\mathrm{N}^{\circ} 18.045$ ), y que entre sus innovaciones existan varias destinadas a flexibilizar la constitución y fiscalización de esta clase de sociedades, especialmente en relación con la información que se proporciona al mercado y con la existencia de un régimen diferenciado para las sociedades anónimas abiertas y cerradas. Desde entonces, toda sociedad anónima se forma, existe y prueba por escritura pública inscrita y publicada en la forma establecida por la Ley $\mathrm{N}^{\circ} 18.046$ y su reglamento (artículo 3 LSA.), sin que sea preciso obtener una autorización previa de parte de la autoridad administrativa ${ }^{68}$. Ella sólo es exigida para los bancos, las compañías aseguradoras y reaseguradoras, las sociedades anónimas administradoras de fondos mutuos, las bolsas de valores y otras sociedades para las que la ley requiera una resolución de la respectiva superintendencia (artículo 126 LSA.).

En materia de agencias de sociedades extranjeras, la Ley $\mathrm{N}^{\circ} 18.046$ mantuvo las reglas existentes en el derecho anterior, con las modificaciones impuestas por la liberalización recién mencionada, de las que trata el título $11^{\circ}$ (artículos 121-124) ${ }^{69}$. De esta forma, ya no es necesario contar con una autorización previa de alguna autoridad administrativa (como podría ser hoy, por ejemplo, la Superintendencia de Valores y Seguros) ${ }^{70}$, y basta con que el agente protocolice en una notaría del lugar donde la sucursal tendrá su domicilio social algunos documentos relativos a la sociedad que representa y su propia personería (artículo 121), además de efectuar, por escritura pública de la misma fecha de la protocolización y ante el mismo notario público, algunas declaraciones que otorguen seguridad a los terceros con que la agencia contratará (artículo 122). Un extracto de la protocolización y de la escritura

${ }^{67}$ Historia de la Ley 18.046 (Santiago, Biblioteca del Congreso Nacional, 1981), pp. 86-88 y 309-311.

${ }^{68}$ Con posterioridad se ha previsto un régimen especial de saneamiento de vicios formales, para evitar que las sociedades comerciales adolezcan de nulidad y sean forzadas a disolverse (Ley $\mathrm{N}^{\circ}$ 19.499). Esta disciplina se aplica también a las cooperativas (artículo 11 LGC.).

${ }^{69}$ Historia de la Ley 18.046, cit. (n. 67), p. 102. Previamente se había dictado un Estatuto de la inversión extranjera (Decreto-ley N 600, de 13 de julio de 1974), en virtud del cual el inversionista puede suscribir un contrato con el Estado que le otorga ciertas prerrogativas, como la invariabilidad tributaria (artículo 8). La reforma tributaria en actual discusión propone su derogación (Boletín $\mathrm{N}^{\circ}$ 9290-05).

${ }^{70}$ Por esta razón, la Superintendencia de Valores y Seguros declaró que era improcedente la revocación del permiso dado para que una agencia funcionase en el país con anterioridad a la Ley $\mathrm{N}^{\circ} 18.046$ (Oficio $\mathrm{N}^{\circ} 58$, de 6 de enero de 1984). 
declarativa del agente se inscribirá en el Registro de Comercio respectivo y se publicará en el Diario Oficial (artículo 123). Las mismas formalidades deberán cumplirse respecto de cualquier modificación que se produzca en relación con los documentos o declaraciones antes mencionadas (artículo 124). De la cancelación de la agencia trata, por su parte, el Reglamento de sociedades anónimas (Decreto supremo $\mathrm{N}^{\circ} 702$, de 6 de julio de 2012, del Ministerio de Hacienda), donde se dispone que dicho trámite deberá ser cumplido por el agente que tenga poder suficiente para ello, y se sujetará a las formalidades exigidas para su establecimiento: escritura pública, inscripción en el Registro de Comercio y publicación en el Diario Oficial (artículo $166)^{71}$. El Reglamento precisa además que el agente puede ser tanto una persona natural como una persona jurídica (artículo 166). Esta disciplina se aplica por remisión a las agencias de bancos (artículo 32 II LGB.), cooperativas (artículo 122 LGC.) y compañías de seguros extranjeras (artículo 4 bis Decreto con fuerza de ley $\mathrm{N}^{\circ} 251 / 1931$ ), con las particularizaciones propias de su régimen.

\section{LA REFORMA DE LA LEY N ${ }^{\circ} 20.382$ Y LA SITUACIÓN ACTUAL DE LAS AGENCIAS}

Una de las reformas más importantes experimentadas por el derecho societario con posterioridad a la promulgación de las Leyes $\mathrm{N}^{\circ} 18.045$ y $\mathrm{N}^{\circ}$ 18.046 provino de la Ley $\mathrm{N}^{\circ} 20.382$, de 20 de octubre de 2009 , que perfecciona la regulación de los gobiernos corporativos ${ }^{72}$. La casi totalidad de las modificaciones que esta ley introduce en el Código de Comercio y en las Leyes de mercado de valores y de sociedades anónimas abocaban al cumplimiento de los siguientes objetivos: $i$ ) aumentar la información que deben entregar las sociedades tanto a sus propios accionistas como a la Superintendencia; ii) asegurar una adecuada fiscalización de los mercados; iii) permitir que en ellos las relaciones entre los distintos agentes sean más fluidas y se adopten mejores decisiones; $\mathrm{y} i v$ ) proteger a los accionistas minoritarios ${ }^{73}$.

Entre las modificaciones concretas introducidas por la Ley 20.382 se

${ }^{71}$ La regla existía ya en el artículo 107 del anterior Reglamento de sociedades anónimas (Decreto supremo $\mathrm{N}^{\circ} 587 / 1982$ ).

${ }^{72}$ Las otras reformas importantes provinieron de las Leyes $\mathrm{N}^{\circ} 19.705$, que reguló las ofertas públicas de adquisición de acciones y los gobiernos corporativos; $\mathrm{N}^{\circ} 20.190$, que introdujo adecuaciones tributarias e institucionales para el fomento de la industria de capital de riesgo y continuó el proceso de modernización del mercado de capitales; y $\mathrm{N}^{\circ} 20.659$, que simplificó el régimen de constitución, modificación y liquidación de las sociedades comerciales.

${ }^{73}$ Historia de la Ley 20.382 (Valparaíso, Biblioteca del Congreso Nacional, 2009), pp. 6-7. 
cuenta la generalización de la figura de la agencia a cualquier sociedad o persona jurídica extranjera con fines de lucro ${ }^{74}$. Para obrar este cometido, se optó por incorporar en el Código de Comercio un párrafo en similares términos de aquel existente en la Ley $\mathrm{N}^{\circ} 18.046$, que disciplina las agencias de todas las otras sociedades (libro II, título $7^{\circ}, \$ 9$, artículos $\left.447-450\right)^{75}$. Hasta entonces, y fuera del ámbito bancario y del comercio de seguros, el único intento de generalización había sido aquel realizado por la Ley $\mathrm{N}^{\circ} 19.832$, que añadió un nuevo artículo 142 a la Ley general de cooperativas contenida en el Decreto supremo 502, de 9 de noviembre de 1978, del Ministerio de Economía, Fomento y Reconstrucción ${ }^{76}$. El texto refundido, coordinado y sistematizado de esta ley está recogido hoy en el Decreto con fuerza de ley $\mathrm{N}^{\circ}$ 5, de 25 de septiembre de 2003, del Ministerio de Economía, Fomento y Reconstrucción, dictado en cumplimiento de la habilitación conferida por la Ley $\mathrm{N}^{\circ} 19.832$. En él se prevé la posibilidad de que las cooperativas extranjeras constituyan una agencia para sus operaciones en Chile según las normas de la Ley 18.046 (artículo 122). Estas agencias quedan sujetas al derecho cooperativo en lo que sea pertinente, pero no gozan de los beneficios tributarios que la ley chilena reconoce a estas entidades. Quedan, por tanto, bajo la supervisión del Departamento de Cooperativas dependiente del Ministerio de Economía, Fomento y Turismo (capítulo IV LGC. y título $9^{\circ}$ RLGC.), y deben inscribirse en el Registro de Cooperativas que lleva este organismo (artículos 9 y 10 RLGC.).

Con la salvedad de este supuesto, las normas referidas a la agencia debían ser interpretadas de manera restringida y, por consiguiente, su aplicación quedaba reservada sólo para el caso de que la sociedad extranjera tuviese el carácter de anónima ${ }^{77}$. Esto no impidió la instalación de agencias de cooperativas extranjeras con anterioridad al reconocimiento de la figura por la Ley 19.832, pero ellas no gozaban de los beneficios tributarios propios de estas asociaciones $^{78}$. Tras la reforma de la Ley $\mathrm{N}^{\circ} 20.382$, en cambio, la disciplina

${ }^{74}$ La idea venía propuesta por ZúÑIga Silva, Agencias de sociedades anónimas, cit. (n. 1), pp. 60-63.

${ }^{75}$ Historia de la Ley 20.382, cit. (n. 73), p. 536.

${ }^{76} \mathrm{La}$ extensión de la agencia respecto de las compañías de seguros extranjeras reproduce el régimen existente en la Ley general de bancos, por la similitud de ambas clases de sociedades (artículo 126 LSA.).

${ }^{77}$ Con anterioridad a la Ley $N^{\circ} 18.046$, la Superintendencia de Sociedades Anónimas había señalado que la exigencia del entonces artículo 122 Decreto con fuerza de ley $\mathrm{N}^{\circ}$ 251/1931 (hoy, artículo 121 LSA.), respecto de la obligación de una sociedad extranjera de actuar en Chile a través de una agencia, sólo resultaba aplicable cuando ella tenía el carácter de sociedad anónima en el país de su domicilio (Oficio $\mathrm{N}^{\circ}$ 5.050, de 1 de septiembre de 1971).

${ }^{78}$ Historia de la Ley 19.832 (Valparaíso, Biblioteca del Congreso Nacional, 2002), p. 840 . 
de la agencia se aplica a cualesquier sociedad o persona jurídica con fines de lucro (artículo 447 CCom.), y también a las cooperativas (artículo 122 LGC.), sin que haya distinción respecto del tipo societario de que se trata. Sólo hay dos excepciones. La primera es más bien de orden teórico y atañe a la sociedad colectiva civil, que no requiere para su formación más que el consentimiento de los socios sobre los aportes y la forma de distribución de las ganancias (artículos 2053 y 2055 CC.). Su carácter consensual hace imposible cumplir con el requisito de formalización del artículo 447 CCom, donde se exige la protocolización de los antecedentes que demuestran la constitución de la sociedad en su país de origen (núm. 1) y de copia auténtica de los estatutos vigentes (núm. 2). La otra excepción tiene mayor relevancia y se refiere a los bancos y compañías de seguros extranjeras, que quedan sujetos a la aprobación de sus respectivas superintendencias en términos semejantes a lo que ocurre con las entidades nacionales que explotan ese giro, fuera de la existencia de ciertas medidas adicionales de resguardo patrimonial por el volumen de sus operaciones ${ }^{79}$.

En la actualidad, entonces, la figura de la agencia se aplica de manera indiferenciada a cualquier persona jurídica con fines de lucro, sin importar su naturaleza civil o comercial. Esto supone que, pese a su ubicación, esta nueva regulación no queda circunscrita a las sociedades comerciales y comprende igualmente a las sociedades civiles (artículos 547 y 2053 CC. y 1 de la Ley $\left.\mathrm{N}^{\circ} 3.918\right)^{80}$. Sólo escapa de este modelo el régimen previsto para las personas sin fines de lucro (artículo 545 CC.), pues en ellas la autorización de funcionamiento y la cancelación siguen siendo de competencia del presidente de la República (artículos 34 y 35 decreto supremo $N^{\circ} 110 / 1979$ ) u hoy, cabría entender, del secretario municipal respectivo (artículo 548 CC. $)^{81}$. En dicha sede, además, no se habla de agente, sino de mandatario,

${ }^{79} \mathrm{La}$ indicación $\mathrm{N}^{\circ} 191$ del presidente Eduardo Frei Ruiz-Tagle agregada al "Segundo informe de la Comisión de Economía” proponía la inclusión de un inciso en el artículo 143, por el cual se excluía la posibilidad de que las cooperativas de ahorro y crédito, de vivienda y de consumo pudiesen operar en Chile como agencias de cooperativas extranjeras o gozasen de los beneficios tributarios que la ley chilena reconoce a estas entidades. Cfr. Historia de la Ley 19.832, cit. (n. 78), p. 593.

${ }^{80} \mathrm{El}$ "Mensaje" del Código de Comercio presenta la disciplina de las sociedades como una particularización de su régimen civil $(\$ 41-47)$, por lo que cabe entender que la inclusión de la agencia entre sus normas no se hace para resguardar la especialidad del derecho comercial (artículo 2 CCom.), sino con el fin de situar en la sede más apropiada unas reglas que comportan el derecho común en la materia (artículo 22 CC.).

${ }^{81}$ En virtud de la Ley $\mathrm{N}^{\circ} 20.500$ se han dictado dos reglamentos, pero ninguno de ellos deroga expresamente el Decreto supremo $\mathrm{N}^{\circ} 110 / 1979$. Tampoco existe derogación tácita, desde que estos reglamentos no contienen disposiciones que no puedan conciliarse con las del Decreto supremo $\mathrm{N}^{\circ} 110 / 1979$ en lo que atañe a la constitución 
y se prevé una revisión de los antecedentes de la persona jurídica extranjera para comprobar cuáles son sus fines, la adecuación con las leyes chilenas y la no contravención del orden público y las buenas costumbres (artículo 34 decreto supremo $\left.\mathrm{N}^{\circ} 110 / 1979\right)^{82}$. Después de la reforma de la Ley $\mathrm{N}^{\circ} 20.500$, el control de mérito que prescribe el actual artículo $548 \mathrm{CC}$. es de meramente carácter formal, dado que sólo se permite al secretario municipal objetar la constitución de una nueva persona jurídica hecha por instrumento público o privado cuando no se hayan cumplido los requisitos que la ley o el reglamento señalan. De momento, y ante la subsistencia material del decreto supremo $\mathrm{N}^{\circ} 110 / 1979$, parecen coexistir dos sistemas distintos referidos a la autorización de funcionamiento de una persona sin fines de lucro (corporaciones y fundaciones de beneficencia pública): $i$ ) uno ante el secretario municipal de su domicilio para las entidades chilenas (artículo 548 CC.); y ii) otro ante el Ministerio de Justicia para las entidades extranjeras que desean constituir en el país un mandatario (artículos 34 y 35 decreto supremo $\mathrm{N}^{\circ} 110 / 1979$ ).

Esta dualidad de regímenes tiene importancia por el cambio que la mentada Ley 20.500 supuso en la tipicidad de las personas jurídicas sin fines de lucro del título $33^{\circ}$ del libro II CC. El nuevo artículo 557-2 CC. permite que las asociaciones y fundaciones realicen actividades económicas que se relacionan con sus fines, y que inviertan sus recursos de la manera que decidan sus órganos de administración, con la sola limitación de que las rentas que perciban se destinen a los fines de la entidad o incrementen su patrimonio. Esto significa que la actividad empresarial no necesariamente se conduce ahora bajo tipos comerciales caracterizados por la búsqueda de un lucro repartible entre los socios, sino también a través de modalidades relacionadas con el interés general (fundaciones y organizaciones comunitarias funcionales) o, al menos, con el interés común de sus asociados (asociaciones y cooperativas), y donde no priman los propósitos puramente crematísticos (artículos 545 CC. y 1 LGC.). La mayor o menor facilidad de constitución contribuirá al empleo de esta forma organizativa como un medio para desarrollar un emprendimiento empresarial por cauces distintos de los ámbitos estatal y capitalista ${ }^{83}$.

de un mandatario que represente en Chile a una asociación o fundación extranjera (artículo 52 III CC.). De hecho, la Editorial Jurídica de Chile incluye todavía ese reglamento de 1979 como parte del apéndice que acompaña la edición oficial del Código Civil.

${ }^{82} \mathrm{El}$ origen de esta norma se encuentra en el artículo 34 del Decreto supremo $\mathrm{N}^{\circ}$ 1.540, de 20 de mayo de 1966, del Ministerio de Justicia, que contenía el anterior Reglamento sobre concesión de personalidad jurídica.

${ }^{83}$ Véase, por ejemplo, EMbid Irujo, J. M., Empresa y fundación en el ordenamiento 


\section{Conclusión:}

\section{SOBRE EL SENTIDO DE LAS AGENCIAS A PARTIR DE SU HISTORIA} LEGISLATIVA

La lección que proporciona este recorrido por la historia legislativa de la agencia de sociedad extranjera atañe a la razón por la cual se previó la figura. Detrás de su disciplina existió un propósito político inicial: que no hubiese en Chile ninguna persona jurídica extranjera que no contase con la previa autorización del Estado para establecerse ${ }^{84}$. Por su propia estructura patrimonial y su difuminado sustrato personal, esta prohibición alcanzaba originalmente sólo a las sociedades anónimas, que era la única clase de empresa que se pensaba era posible de deslocalizar para extender su campo de operaciones ${ }^{85}$. El recelo hacia este tipo societario provenía, además, de que él podía constituir un instrumento de fraude para obtener cuantiosas sumas provenientes de los ahorros de la colectividad, o bien un medio de presión hacia el Estado en razón de la fuerza económica que da a esta clase de compañías un capital que, en principio, es capaz de crecer constantemente por captación directa o reinversión ${ }^{86}$. De ahí que la disciplina de la agencia, inicialmente prevista en el Código de Comercio, se desarrollase a propósito de ámbitos en extremo susceptibles para la economía, como el comercio de seguros (para el cual Ocampo pensó la figura y donde llegó a prohibirse completamente) y la actividad bancaria. Cabe preguntarse entonces si hoy en día, con un régimen de libertad de constitución como el que impera desde la promulgación de la Ley 18.046 (relacionado con la garantía del artículo $19 \mathrm{~N}^{\circ} 21$ CPol.) y hacia el que avanzan las reformas introducidas respecto de las personas jurídicas sin fines de lucro (Leyes $\mathrm{N}^{\circ} 19.638$ y $\left.\mathrm{N}^{\circ} 20.500\right)^{87}$,

español (la fundación empresaria), en Anuario de Derecho de Fundaciones (2010), pp. $15-67$.

${ }^{84} \mathrm{La}$ regla alcanzaba incluso a las personas jurídicas de naturaleza eclesiástica, como después quedó recogido en los proyectos de concordato preparados tras la Constitución Politica de 1925. Véase, con texto y comentario: Salinas Araneda, C., Un primer proyecto de concordato entre Chile y la Santa Sede en 1928, en Revista Chilena de Derecho, 29 (2012) 3, pp. 681-683.

${ }^{85}$ Véase las razones que da Pardessus, J. M., Cours de droit commercial (París, Henri Plon, 6a ed., 1857), III, núm. 1039 (pp. 136-137) y 140 (pp. 142-143), sobre la existencia de la sociedad anónima y la necesidad de una autorización administrativa para su funcionamiento.

${ }^{86}$ FernÁndez Villamayor, La sociedad anónima, cit. (n. 8), p. 23.

${ }^{87}$ Del Picó Rubio, J., Modificación del régimen civil de las personas sin fines de lucro a partir de la vigencia de las Leyes $N^{\circ} 19.638$ y $N^{\circ} 20.500$, en ElorRiaga De BoNIS, F. (coordinador), Estudios de derecho civil VII (Santiago, Abeledo Perrot - ThomsonReuters, 2012), pp. 17-27. 
se justifica la existencia del actual régimen de la agencia fuera de consideraciones fiscales que fácilmente podrían solventarse de otra manera, dado que el reconocimiento de la personalidad jurídica de una sociedad extranjera no se pone en duda (artículos 34 y 252 del Código de Derecho Internacional Privado ${ }^{88}$. Dicho de otra forma, la cuestión de política legislativa que hay detrás es si la disciplina de la agencia satisface sólo requerimientos de tributación, para lo que bastaría la inscripción en el rol único tributario que lleva el Servicio de Impuestos Internos (artículo 66 CT.), o también tiene implicancias sustantivas, relacionadas con la protección de los acreedores chilenos, como parecen demostrarlo las quiebras declaradas en el país ${ }^{89}$. Los antecedentes revisados permiten concluir que el conflicto de intereses se resuelve en la actualidad a favor del Estado, en desmedro de los créditos derivados de la actuación de la agencia en el país.

La tendencia histórica aquí revisada apunta hacia una formalización automática de la agencia, sin mayor control de la autoridad pública (muchas veces ella misma difuminada, como ocurre respecto de las sociedades que no revisten la calidad de anónimas abiertas). Ella parece estar enderezada a la captura de rentas ("rent-seeking") por vía impositiva, lo que se logra a través del reconocimiento de los establecimientos permanentes dentro de la categoría de contribuyente (artículo $8 \mathrm{~N}^{\circ} 5 \mathrm{CT}$.). Sin embargo, este efecto no debe hacer olvidar la utilidad y beneficios sociales del registro ${ }^{90}$, pues cuando se minusvaloran las ventajas de la formalización y se asume que no varían las consecuencias entre las distintas soluciones, el modelo de simplificación acaba reducido a un intento de suprimir o, con más frecuencia, comprimir los trámites sin atender al valor de los servicios que ella presta ${ }^{91}$. En otras palabras, con un sistema de registro automático generalizado se consigue de manera eficaz la finalidad de gravar la actividad económica que las empresas extranjeras realizan en el país, pero quedan fueran los beneficios que el sistema registral presta al mercado y a la propia Administración en otros ámbitos.

${ }^{88}$ Originalmente negada por Alessandri Rodríguez, A., ¿Puede una persona jurídica extranjera ser instituida asignataria de bienes situados en Chile? en Revista de Derecho y Jurisprudencia, 17 (1920), pp. 53-68, no hay duda de su reconocimiento desde Claro Solar, L. Explicaciones de derecho civil chileno y comparado (Santiago, Cervantes, 1929), V, núm. 2790, pp. 499-500; y del Oficio $\mathrm{N}^{\circ} 352$, de 7 de junio de 1935, de la Superintendencia de Sociedades Anónimas.

${ }^{89}$ Por ejemplo: “Air Madrid Agencia en Chile”, $17^{\circ}$ Juzgado Civil de Santiago (rol $\mathrm{N}^{\circ}$ 23.644-2006); "March South America Holdings Limited Agencia en Chile", $7^{\circ} \mathrm{Juz}-$ gado Civil de Santiago (rol N ${ }^{\circ}$ 24.633-2009); "Relacom Internacional Holland B.V. Agencia en Chile”, $17^{\circ}$ Juzgado Civil de Santiago (rol N ${ }^{\circ} 11.565-2012$ ).

${ }^{90}$ Cfr. "Mensaje” del Código de Comercio, $\$ 19$.

${ }^{91}$ ArRuñadA, B., Fundamentos institucionales de la contratación empresarial: una teoria del Registro de Comercio, en Revista de Derecho Mercantil, 278 (2010), p. 1301. 
De forma refleja, esto aboca a una pregunta que aquí no cabe abordar, relacionada con la función que han de desempeñar los notarios y el Registro de Comercio en la protección del tráfico mercantil. Su actual configuración no les concede competencias de calificación registral, de suerte que dichos auxiliares de la administración de justicia carecen de la posibilidad de controlar la legalidad y la validez del contenido de los actos y acuerdos sociales y de la capacidad y legitimación de quienes los suscriben ${ }^{92}$. Su cometido se agota en revisar las formas del documento que se les presenta (artículos 401 y 405 COT, 20 CCom. y 18 RRC.). Si esto es así, las exigencias de establecimiento de una agencia que fueron pensadas para un sistema de control efectivo por parte de la Administración, para comprobar que no hubiere perjuicios a los accionistas de la sociedad extranjera o a sus acreedores chilenos derivados de un fraude de ley o de la ausencia de capital efectivo para su funcionamiento en el país, son hoy meramente programáticas fuera del caso de las sociedades anónimas sujetas a una autorización de existencia de parte de la respectiva superintendencia (artículo 126 III LSA.), donde además existen otros resguardos patrimoniales. Una revisión profunda del régimen de la agencia, incluida la conveniencia de su conservación, es todavía una tarea pendiente y conexa con la reforma del régimen de notarios y conservadores (Boletin No 8351-07).

\section{Bibliografía}

Albornoz Robertson, J., El establecimiento permanente, en Revista de Derecho, 11 (Valdivia, 2000).

Alcalde Silva, J., Apuntes sobre la agencia de sociedad extranjera, en Jequier LeHuedÉ, E. (editor), Estudios de derecho comercial (Santiago, LegalPublishing/ ThomsonReuters, 2014) [en prensas], II.

Alessandri Rodríguez, A., ¿Puede una persona jurídica extranjera ser instituida asignataria de bienes situados en Chile? en Revista de Derecho y Jurisprudencia, 17 (1920).

ANDrades Rivas, E., La sociedad anónima en la tradición jurídica hispano-indiana, en Revista de Estudios Histórico-Jurídicos, 33 (2011).

Aránguiz Donoso, H., Notas para el estudio de los bancos extranjeros en Chile: 18891971, en Historia, 27 (1993).

${ }^{92}$ De hecho, el artículo 8 RRC. difiere del artículo 13 RRCBR. en lo que atañe a los supuestos que autorizan al Conservador para rechazar una inscripción. En este último hay una mención genérica a la causa que habilita para rehusar tal trámite ("si la inscripción es en algún sentido legalmente inadmisible”), y entre los ejemplos mencionados se cuenta el de ser ostensible en el título algún vicio o defecto que lo anule absolutamente; mientras que en el primero se enumeran taxativamente ("no puede dimanar de otras causas que de [...]") unas causas de rechazo de carácter meramente formal. 
ARRUÑADA, B., Fundamentos institucionales de la contratación empresarial: una teoría del Registro de Comercio, en Revista de Derecho Mercantil, 278 (2010).

Brady Roche, E., Situación legal de las agencias de compañias extranjeras de seguros (Santiago, Universidad de Chile, 1945).

Brahm García, E., José Gabriel Ocampo y las fuentes de la Ley sobre sociedades anónimas. El proceso de codificación comercial chileno en un ejemplo, en Revista de Estudios Histórico-Jurídicos, 19 (1997), ahora en José Gabriel Ocampo y la codificación comercial chilena (Santiago, Universidad de los Andes, 2000), I.

Caballero Germain, G., Presente y futuro de la Superintendencia de Valoresy Seguros, en Revista Chilena de Derecho Privado, 11 (2008).

CÁRdenas, F. (editor), El Derecho moderno. Revista de Jurisprudenciay Administración (Madrid, Ramón Rodríguez de Rivera, 1847), II.

Cattaneo Escobar, I., Naturaleza juridica de las normas sobre impuesto a las rentas en la República, previos a la Ley No.3996, en Revista Chilena de Historia del Derecho, $23(2011)$.

Claro Solar, L. Explicaciones de derecho civil chileno y comparado (Santiago, Cervantes, 1929), V.

Claro Solar, L., La ley No 3.918 de 14 de marzo de 1923 sobre sociedades de responsabilidad limitada, en Revista de Derecho y Jurisprudencia, 20 (1923).

Congreso Nacional, Sesiones ordinarias de la Cámara de Diputados de 1885 (Santiago, Imprenta Nacional, 1885).

Courcelle-Seneuil, J. G., Bancos de circulación, en Revista de Ciencias i Letras, 1 (1857).

Couyoumdjian, J. R., Los británicos en las finanzas/British Influence on Financial Management, en PraIn, M. (editor), Legado británico en Valparaiso/British Legacy in Valparaiso (Santiago, RIL, 2010).

Del Picó Rubio, J., Modificación del régimen civil de las personas sin fines de lucro a partir de la vigencia de las Leyes $N^{\circ} 19.638$ y $N^{\circ} 20.500$, en ElORRIAGA De Bonis, F. (coordinador), Estudios de derecho civil VII (Santiago, Abeledo Perrot - ThomsonReuters, 2012).

Devilleneuve, L. M.- Carrete, A. A., (editores), Recueil général des lois et des arrêts avec notes et commentaires, I : Lois annotées. 1789-1830 (Paris, Administration du Recueil général de lois et arrêts, 1851).

Embid Irujo, J. M., Empresa y fundación en el ordenamiento español (la fundación empresaria), en Anuario de Derecho de Fundaciones (2010).

Espinosa Moder, A., Régimen legal del comercio de seguros en Chile (Santiago, Imprenta Electra, 1928).

Espinosa Moder, E., Los seguros en Chile (memoria de prueba, Santiago, Facultad de Comercio y Ciencias Económicas, Universidad Católica de Chile, 1932).

Eyzaguirre Pepper, D., Agencias de sociedades anónimas extranjeras (Santiago, Pontificia Universidad Católica de Chile, 1981).

FERnÁNDEZ OJEDA, M. (coordinador), Disposiciones vijentes en Chile sobre instituciones de crédito i comerciales: bancos, seguros, sociedades, comercio, contribuciones (Santiago, s.e., 1923).

FERNÁNDEZ Villamayor, A., La sociedad anónima con las reformas introducidas por la Ley núm. 17.308 de 1970 (Santiago, Editorial Jurídica de Chile, s.d. [pero 1970]).

HeLd, G. - JimÉNEZ, L. F., Liberalización, crisis y reforma del sistema bancario: 1974-99, en FFrench-Davis, R. - Stallings, B. (editores), Reformas, crecimiento y politicas sociales en Chile desde 1973 (Santiago, LOM/CEPAL, 2001).

Historia de la Ley 18.046 (Santiago, Biblioteca del Congreso Nacional, 1981). 
Historia de la Ley 19.832 (Valparaíso, Biblioteca del Congreso Nacional, 2002). Historia de la Ley 20.190 (Valparaíso, Biblioteca del Congreso Nacional, 2007). Historia de la Ley 20.382 (Valparaíso, Biblioteca del Congreso Nacional, 2009). Historia de la Ley 20.667 (Valparaíso, Biblioteca del Congreso Nacional, 2013).

Illanes Adaro, R., Agencias de sociedades anónimas extranjeras (Santiago, Universidad de Chile, 1941).

Koвetsky, M., International Taxation of Permanent Establishments. Principles and Policy (Cambridge, CUP, 2011).

La Chilena Consolidada, Reseña histórica de sus noventa años de vida. 1853-1943 (Valparaíso, Imprenta Universo, 1944).

Legislación bancaria y monetaria (Santiago, Imprenta Universitaria, 1926), ahora reeditado como vol. 82 de la Biblioteca Fundamentos de la Construcción de Chile (Santiago, Biblioteca Nacional/Pontificia Universidad Católica de Chile/Cámara Chilena de la Construcción, 2011), con un estudio preliminar de Juan Pablo Couyoumdjian.

Maldonado Vargas, C., Extensión del concepto de establecimiento permanente en el derecho chileno y su adecuación a los convenios modelo OCDE (tesis para optar al grado de Magíster en Derecho Tributario, Santiago, Universidad de Chile, 2012).

"Mensaje" del Código de Comercio.

Molina Moreno, G - Pellegrini Ripamonti, P., Agencia de sociedad anónima extranjera (Santiago, Pontificia Universidad Católica de Chile, 1988).

Morales Alfaro, J. E. y otros, Análisis del impacto de las interpretaciones del Servicio de Impuestos Internos relacionada con las agencias extranjeras con motivo de las reinversiones contenidas en el DL 824 en su articulo 14 de la LIR (Santiago, Universidad Diego Portales, 2004).

Morand Valdivieso, L., Legislación bancaria (5ª edición, Santiago, Editorial Jurídica de Chile, 2008).

Pardessus, J. M., Cours de droit commercial (París, Henri Plon, 6a ed., 1857), III.

ReInstein, A. - Rosende, F., Reforma financiera en Chile, en LARraín, F. - Vergara, R. (editores), La transformación económica de Chile (Santiago, CEP, 2000).

Rivas Vicuña, M., Historia política y parlamentaria de Chile. 1891-1920 (Santiago, Biblioteca del Congreso Nacional, 1964), I.

Rojas SÁnchez, G. (editor), Historia del gremialismo empresarial (Santiago, Confederación de la Producción y el Comercio, 2000).

Salinas Araneda, C., Un primer proyecto de concordato entre Chile y la Santa Sede en 1928, en Revista Chilena de Derecho, 29 (2012) 3.

Schadlich, U., Antecedentes históricos y doctrinarios de la legislación de seguros en Chile (Santiago, Editorial Universitaria, 1963).

Torechio, D., Hechos de Chile (Santiago, Sociedad Filatélica de Chile, 1982).

Ugarte Vial, J. (director), Historia e indice de las leyes (Santiago, Biblioteca del Congreso Nacional, 1950), II.

Villalobos Rivera, S., Comercio y contrabando en el Río de la Plata y en Chile. 17001811 (Buenos Aires, EUDEBA, 1965).

Vivanco Silva, S., Procedencia y dificultades de la declaración de quiebra de una agencia de sociedad anónima extranjera (Santiago, Pontificia Universidad Católica de Chile, 1997).

Zúñiga Silva, M. ${ }^{a}$ C., Agencias de sociedades anónimas extranjeras. Análisis crítico y ámbito de aplicación (Santiago, Pontificia Universidad Católica de Chile, 1998). 

